Uma biblioteca para a simulação de protocolos de entrega de mensagens em redes móveis.

Weslley Emmanuel Martins Lima

DISSERTAÇÂO DE MESTRADO APRE_ $\quad$ ADA AO INSTITUTO DE MATEMÁTICA E ESTATÍSTICA DA UNIVERSIDADE DE SÃO PAULO PARA OBTENÇ,ÃO DO GRAU DE MESTRE EM CIÊNCIA DA COMPUTAÇÃO

Curso: Mestrado em Ciência da Computação Área de Concentração: Sistemas Distribuídos Orientador: Prof. Dr. Alan Mitchell Durham 


\title{
Uma biblioteca para simulação \\ de protocolos de entrega de mensagens em redes móveis.
}

\author{
Este exemplar corresponde à redação final da \\ dissertação devidamente corrigida e defendida \\ por Weslley Emmanuel Martins Lima e apro- \\ vada pela comissão julgadora.
}

São Paulo, 16 de junho de 2003

Banca examinadora:

Prof. Dr. Alan Mitchel Durham (orientador) IME-USP

Prof. Dr. Fábio Kon

IME-USP

Prof. Dr. Antonio Alfredo Ferreira Loureiro

DCC-UFMG 
Navegadores antigos tinham uma frase gloriosa: "Navegar é preciso; viver não é preciso." Quero para mim o espírito desta frase, transformada a forma para a casar com o que eu sou: Viver não é necessário; o que é necessário é criar.

Não conto gozar a minha vida; nem em gozá-la penso. Só quero torná-la grande, ainda que para isso tenha de ser o meu corpo e a minha alma a lenha desse fogo. Só quero torná-la de toda a humanidade; ainda que para isso tenha de a perder como minha. Cada vez mais assim penso. Cada vez mais ponho na essência anímica do meu sangue o propósito impessoal de engrandecer a pátria e contribuir para a evolução da humanidade.

(texto do livro "Fernando Pessoa - Obra Poética") 


\section{Agradecimentos}

Em primeiro lugar, agradeço a Deus por olhar por mim durante toda essa longa caminhada. Sinto sua presença em cada momento da minha vida.

Agradeço em especial à Rosianni que foi durante esses mais de 2 anos, um pouco de tudo em minha vida: namorada, amiga, irmã. Esteve sempre ao meu lado nos maus e bons momentos. Espero que continuemos assim para todo o sempre. Essa vitória também é sua!

Ao Alan, pela ótimo trabalho de orientação. Sua participação foi fundamental para o desenvolvimento deste trabalho. Sua conduta me servirá de exemplo.

Ao Professor Markus Endler que, mesmo à distância, contribuiu decisivamente para o desenvolvimento deste trabalho, indicando livros e artigos relacionados ao tema.

Aos professores Fábio Kon e Loureiro pelos ótimo comentários durante a defesa que contribuíram bastante para melhorar a qualidade do trabalho.

A meu Pai, minha Mãe e minhas irmãs dos quais tive que abrir mão da convivência durante todo esse tempo. Obrigado pelo apoio financeiro e, principalmente, moral. A certeza de que um dia voltaria para perto de vocês me deu forças para ir até o fim.

Ao Carlos, um amigo de longa data com quem compartilhei momentos legais e que contribuiu, sempre que possível, para a realização deste trabalho.

Aos amigos que fiz no IME: Mateus, Leandro, Ana Lúcia, Francisco, Alessandro, Alexandre e Braga que fizeram dessa minha passagem por São Paulo muito agradável.

À Tia Conceição e ao Vovô Antonino que com certeza torceram por mim de onde quer que estejam. 


\section{Resumo}

Os grandes avanços tecnológicos ocorridos nos últimos anos propiciaram a criação de um novo modelo de comunicação chamado computação móvel. Com esse novo modelo, novos fatores devem ser considerados na criação de aplicações em sistemas distribuídos. Diante disso torna-se necessário adaptar os algoritmos existentes ou até mesmo criar novos.

A necessidade de se considerar a mobilidade na construção de protocolos distribuídos aumenta a complexidade de validação dos algoritmos distribuídos. Uma técnica que auxilia a avaliação de protocolos de rede são os simuladores.

Diversos mecanismos de recuperação de informação são oferecidos a clientes móveis. Serviços esses que se utilizam de uma classe específica de protocolos distribuídos. São os chamados protocolos de entrega de mensagens.

Esta dissertação analisa a classe de protocolos de entrega de mensagens através da coleta, especificação e análise dos principais protocolos existentes. O estudo desses protocolos permitiu-nos abstrair as funcionalidades comuns culminando na implementação de uma biblioteca, associada a um simulador chamado MobiCS, composta por todas as partes fatoradas. 


\section{Sumário}

1 Introdução

2 Simuladores de protocolos para redes móveis 4

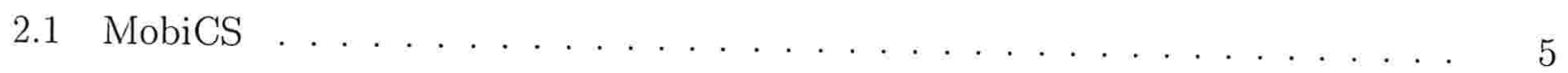

2.2 x-kernel e Coyote . . . . . . . . . . . . . . . . . . 6

2.3 GloMoSim . . . . . . . . . . . . . . . . . . . . . 7

2.4 Ns . . . . . . . . . . . . . . . . . . . . . . . . 9

3 Protocolos para entrega de mensagens em redes móveis 11

3.1 Modelo do Sistema . . . . . . . . . . . . . . . . . . . 12

3.2 RDP . . . . . . . . . . . . . . . . . . . . . . . 14

3.2 .1 Funcionamento . . . . . . . . . . . . . . . 15

3.2 .2 Informações mantidas pelo sistema . . . . . . . . . . . . 17

3.2 .3 Especificação das Mensagens . . . . . . . . . . . . . . . . . 17

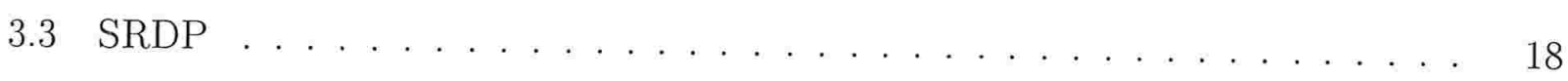

3.3 .1 Funcionamento . . . . . . . . . . . . . . . . . 18

3.3 .2 Informações mantidas pelo sistema . . . . . . . . . . . . . . . . 19

3.3.3 Especificação das Mensagens . . . . . . . . . . . . . . . . . . . . 19

3.4 Mobile IP Adaptado . . . . . . . . . . . . . . . . . . . . . . 20 
3.4 .1 Funcionamento . . . . . . . . . . . . . . . . . 21

3.4 .2 Informações mantidas pelo sistema . . . . . . . . . . . . . . 23

3.4.3 Especificação das Mensagens . . . . . . . . . . . . . . . . . 23

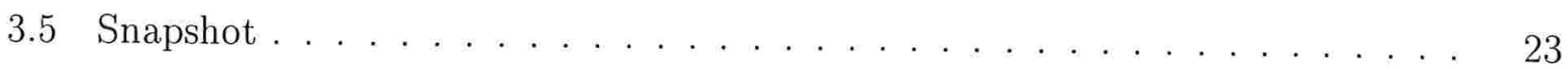

3.5 .1 Funcionamento . . . . . . . . . . . . . . . 24

3.5 .2 Informações mantidas pelo sistema . . . . . . . . . . . . . 26

3.5.3 Especificação das Mensagens . . . . . . . . . . . . . . . . . 27

3.6 Análise Comparativa . . . . . . . . . . . . . . . . . . 27

4 A Biblioteca 31

4.1 Motivação . . . . . . . . . . . . . . . . . . . . . . 31

4.2 Programação de protocolos no MobiCS . . . . . . . . . . . . . . . 33

4.2 .1 Implementação do RDP no MobiCS . . . . . . . . . . . . . . . . . 37

4.3 Modificações realizadas no MobiCS . . . . . . . . . . . . . . . . . . 40

4.4 Arquitetura do Sistema . . . . . . . . . . . . . . . . . . 43

4.4 .1 Componentes do sistema . . . . . . . . . . . . . . 45

4.4 .2 As mensagens da Biblioteca . . . . . . . . . . . . . . 51

4.4 .3 O pacote estocástico . . . . . . . . . . . . . . . 52

5 O uso da biblioteca $\quad 56$

5.1 Protocolos Implementados . . . . . . . . . . . . . . . . . . . 56

5.2 Implementação do protocolo RDP . . . . . . . . . . . . . . . . . . . 57

5.3 Resultados Obtidos . . . . . . . . . . . . . . . . . . . . . 61

6 Conclusões e Trabalhos Futuros $\quad 69$ 


\section{Capítulo 1}

\section{Introdução}

Os grandes avanços tecnológicos ocorridos nos últimos anos propiciaram a criação de um novo modelo de comunicação, no qual computadores portáteis podem comunicar-se com uma rede fixa ou com outros computadores portáteis independente da sua localização física. Esse novo modelo é chamado de computação móvel [DFJ91].

O aumento no poder de processamento e na quantidade de memória dos dispositivos portáteis e uma queda acentuada do preço tem tornado esse tipo de tecnologia cada vez mais popular. Sua utilização pode ser vista nos sistemas de telefonia celular que se expandem de maneira acelerada. No Brasil, segundo dados do Ministério da Ciência e Tecnologia [Tak00], em 1994 haviam 800 mil pessoas com telefone celular, em julho de 1998 já eram 5,6 milhões de aparelhos em uso, chegando a 15 milhões de aparelhos em operação em dezembro de 1999.

A criação desse novo modelo de comunicação traz à tona um grande empecilho no que se refere às aplicações em sistemas distribuídos: Grande parte dos algoritmos distribuídos foram projetados para redes em que todas as máquinas do sistema possuem uma localização fixa e bem conhecida. Segundo Badrinath et al. [BAI93], a mobilidade introduz um conjunto de novos fatores que não existiam nos sistemas distribuídos convencionais: 
- Para entregar uma mensagem a uma unidade móvel, é preciso localizá-la dentro do sistema. Existem duas possibilidades: manter a informação atualizada da localização da unidade móvel ou buscá-la no sistema quando necessário;

- A qualidade da conexão com a rede pode variar a cada migração da unidade móvel;

- Devido à energia limitada, é necessário que as unidades fiquem num estado de "Cochilo" para redução do consumo de energia ou até mesmo permaneçam desconectadas por um longo tempo;

- A largura de banda do meio sem fio é pequena quando comparada com a rede fixa;

- O meio sem fio é muito suscetível a interferências (ruído, atenuação) que afetam diretamente a taxa de erro. De acordo com Mateus e Loureiro [ML98], a taxa de erro na comunicação sem fio é de cinco a dez ordens de grandeza maior que na rede fixa.

Dessa forma, os algoritmos devem considerar tais fatores durante o processo de comunicação com a unidade móvel, buscando minimizar o tráfego pelo meio sem fio. Tal fato evidencia a necessidade de criar novos algoritmos distribuídos ou até mesmo adaptar os existentes para que considerem tais fatores durante o processo de comunicação entre as unidades (fixas e/ou móveis) do sistema. Esta dissertação faz um estudo dos protocolos que tratam o problema de entrega de mensagens unicast.

Os protocolos de entrega de mensagens são utilizados principalmente em mecanismos de recuperação de informação oferecidos a clientes móveis $\left[\mathrm{ESS}^{+} 00, \mathrm{FJL}^{+}\right.$99, $\mathrm{DPS}^{+}$94]. Esses protocolos permitem atualização e consulta a bases de dados em servidores distribuídos e são adequados a serviços de rede baseados no estilo requisição-resposta.

O foco principal deste trabalho é analisar todas as características da classe de protocolos que segue o modelo pergunta/resposta. Foram coletados, especificados e comparados os principais protocolos de entrega de mensagens visando determinar as funcionalidades comuns. 
Para permitir a avaliação dos protocolos aqui estudados, optou-se por utilizar o simulador MobiCS [Roc01] que permite a simulação de protocolos de alto nível. O MobiCS foi escolhido por ser um simulador que permite uma prototipagem rápida de protocolos através de abstrações de alto nível sem forçar o usuário a realizar um detalhamento excessivo do ambiente simulado.

Como conseqüência, esta dissertação descreve uma extensão na arquitetura do MobiCS contendo toda a funcionalidade comum à classe de protocolos em questão a fim de permitir sua reutilização, bem como permitir a criação de novos protocolos. O objetivo é criar um conjunto de classes a fim de reduzir significativamente o trabalho do usuário na descrição de um novo protocolo.

Esta dissertação possui a seguinte organização: O capítulo 2 descreve os principais trabalhos relacionados existentes e mostra os principais pontos que os relacionam a este trabalho. O capítulo 3 descreve o modelo de sistema adotado e os principais protocolos para entrega de mensagens existentes fazendo uma análise comparativa entre eles. O capítulo 4 faz uma descrição dos principais conceitos relacionados a arcabouços mostrando as vantagens de se utilizar tal técnica de construção de aplicações e apresenta a arquitetura da biblioteca mostrando a estrutura de classes $^{1}$ que a compõe e descrevendo os seus principais componentes. O capítulo 5 descreve os passos da implementação de um dos protocolos, o protocolo RDP. Mostra que protocolos foram implementados e a quantidade de linhas necessárias a essa implementação com e sem o uso da biblioteca. Além disso, descreve testes realizados a fim de comprovar que a utilização da biblioteca não altera de maneira considerável o desempenho. Por fim, no capítulo 6, são mostradas algumas conclusões e trabalhos futuros propostos.

\footnotetext{
${ }^{1}$ Os nomes de todas os métodos e classes estão em inglês por uma questão de compatibilidade com o simulador MobiCS
} 


\section{Capítulo 2}

\section{Simuladores de protocolos para redes}

\section{móveis}

Segundo Rocha [Roc01], os simuladores para computação móvel podem ser classificados em simuladores de rede e simuladores de protocolos. Os simuladores de redes são projetados para simular características específicas de uma rede. Por exemplo, Liljenstam [LA97] descreve um simulador para redes de comunicação pessoal (PCNs), chamado MobSim++, que foi projetado principalmente para analisar o desempenho dos mecanismos de gerenciamento de recursos. Já os simuladores de protocolos são construídos de forma a permitir a implementação e o teste de protocolos para um ambiente de rede simulado.

Dentre as classes de simuladores, este trabalho aborda os simuladores de protocolos. A escolha fundamenta-se na idéia de que os simuladores de protocolos são mais genéricos que os simuladores de rede, abrangendo um número maior de protocolos que podem ser avaliados.

No restante deste capítulo descrevemos alguns dos principais simuladores de protocolos. A seção 2.1 descreve brevemente o simulador MobiCS. A seção 2.2 descreve o x-Kernel, um arcabouço orientado a objetos para implementação hierárquica de protocolos de rede. A seção 2.3 mostra uma biblioteca para simulação de redes sem fio chamada GloMoSim e 2.4 
descreve o Ns, um simulador baseado em eventos discretos que permite a simulação dos mais variados protocolos de rede.

\subsection{MobiCS}

MobiCS é "um simulador de protocolos distribuídos para computação móvel, que integra em uma única ferramenta a prototipagem, teste, validação e avaliação de protocolos distribuídos. O simulador facilita a programação de protótipos de protocolos, tendo como base um modelo de programação modular e orientado a eventos, baseado no conceito de micro-protocolos" [Roc01].

Várias características deste simulador o diferenciam de outros simuladores de protocolos. Primeiramente, permite uma prototipagem rápida de protocolos uma vez que não necessita de um detalhamento excessivo do ambiente simulado. Além disso, possui dois modos de simulação diferentes: o determinístico, que permite testar situações críticas do protocolo onde ele poderia eventualmente falhar, e o estocástico, para submetê-lo a simulações mais gerais, visando observar o seu desempenho.

Uma outra característica importante deste simulador é a possibilidade de se realizar os dois tipos de simulação sem que seja necessário qualquer alteração no código que implementa a descrição dos protocolos.

Este simulador foi adotado como base para este trabalho devido a todas a facilidades que ele proporciona na simulação de protocolos para computação móvel. A adoção do MobiCS também ocorreu pela disponibilidade do código-fonte para eventuais alterações e principalmente por estar inserido no mesmo contexto em que está sendo desenvolvido este trabalho, o projeto SIDAM [ESS $\left.{ }^{+} 00\right]$. No Capítulo 4, é feita uma descrição mais detalhada deste simulador. 


\section{2 x-kernel e Coyote}

O x-kernel [HP91], desenvolvido na Universidade do Arizona, define uma interface que protocolos de rede usam para invocar operações de outros protocolos e possui uma biblioteca com a implementação dos principais protocolos de rede. Para o x-kernel, um protocolo é visto como uma especificação de uma abstração de comunicação através da qual uma coleção de participantes trocam mensagens entre si.

Para prover esse modelo, o x-kernel provê três objetos primitivos de comunicação: protocolos, sessões e mensagens. Os objetos-protocolo correspondem aos protocolos de rede convencionais, por exemplo, TCP, IP e UDP. Os objetos-sessão representam uma conexão entre objetos-protocolo com as estruturas de dados que representam o estado local da referida conexão de rede. Já os objetos-mensagem contém os dados a serem transmitidos e um ou mais cabeçalhos de protocolos.

Coyote [BHSC98] é um sistema que permite a construção de protocolos de alto nível de maneira altamente modular e configurável. É uma extensão do x-kernel que além da composição vertical, na qual protocolos são organizados em uma estrutura hierárquica de camadas, possibilita também uma composição horizontal de protocolos em que os protocolos de cada camada podem ser compostos por estruturas de granularidade mais fina. Coyote faz um refinamento do conceito de protocolo, introduzindo o conceito de micro-protocolos que são entidades que implementam funcionalidades específicas (por exemplo, ordenação e confirmação) como módulos separados. Um protocolo passa a ser composto por um conjunto de micro-protocolos que implementam sua funcionalidade. Esse refinamento advindo do conceito de micro-protocolos faz do Coyote um ambiente de granularidade mais fina quando comparado ao x-kernel.

O x-kernel está relacionado ao escopo deste trabalho na medida em que é um arcabouço para implementação de protocolos através da composição de protocolos existentes como, 
por exemplo, IP, UDP e TCP. Para isso, o x-kernel provê uma interface uniforme entre os protocolos que evita o custo adicional na mudança das abstrações. Desta forma, facilita a construção e o teste de novos protocolos. Já Coyote está intimamente relacionado a MobiCS pois o seu modelo de programação de protocolos, baseado em micro-protocolos, foi adotado como base para a criação de MobiCS. Além de utilizar-se da idéia de micro-protocolos, MobiCS permite também a construção de simulações diferentes sobre um mesmo protocolo sem qualquer alteração no seu código, que o diferencia do Coyote.

\subsection{GloMoSim}

GloMoSim (Global Mobile system Simulator) [ZBG98] é uma biblioteca para simulação de redes sem fio. Para desenvolvê-la foi utilizada uma linguagem de simulação paralela baseada em C, chamada PARSEC [BMT+98]. Esta linguagem é utilizada para a criação de novos protocolos que podem ser adicionados à biblioteca.

A arquitetura do GloMoSim é baseada em camadas como mostrado na figura 2.1. Cada camada contém inúmeras possibilidades de protocolos que podem ser utilizados para as mais variadas composições de protocolos. Para permitir esta composição, foi definida uma interface que especifica os serviços e os parâmetros trocados entre duas camadas vizinhas.

Inicialmente GloMoSim foi projetado de maneira que, em uma simulação, cada nó da rede fosse mapeado para um objeto da simulação chamado de entidade. No entanto, alguns experimentos realizados pelos próprios projetistas do GloMoSim mostraram que simulações com um número muito elevado de objetos de simulação levam a uma grande sobrecarga. Para solucionar esse problema, GloMoSim divide a rede em partições. Cada camada da pilha de protocolos, para todos os nós de uma dada partição, é representada por uma única entidade.

Existem duas possibilidades para se compor a pilha de protocolos partindo das entidades existentes: Através de uma especificação textual dentro de uma entidade de inicialização es- 


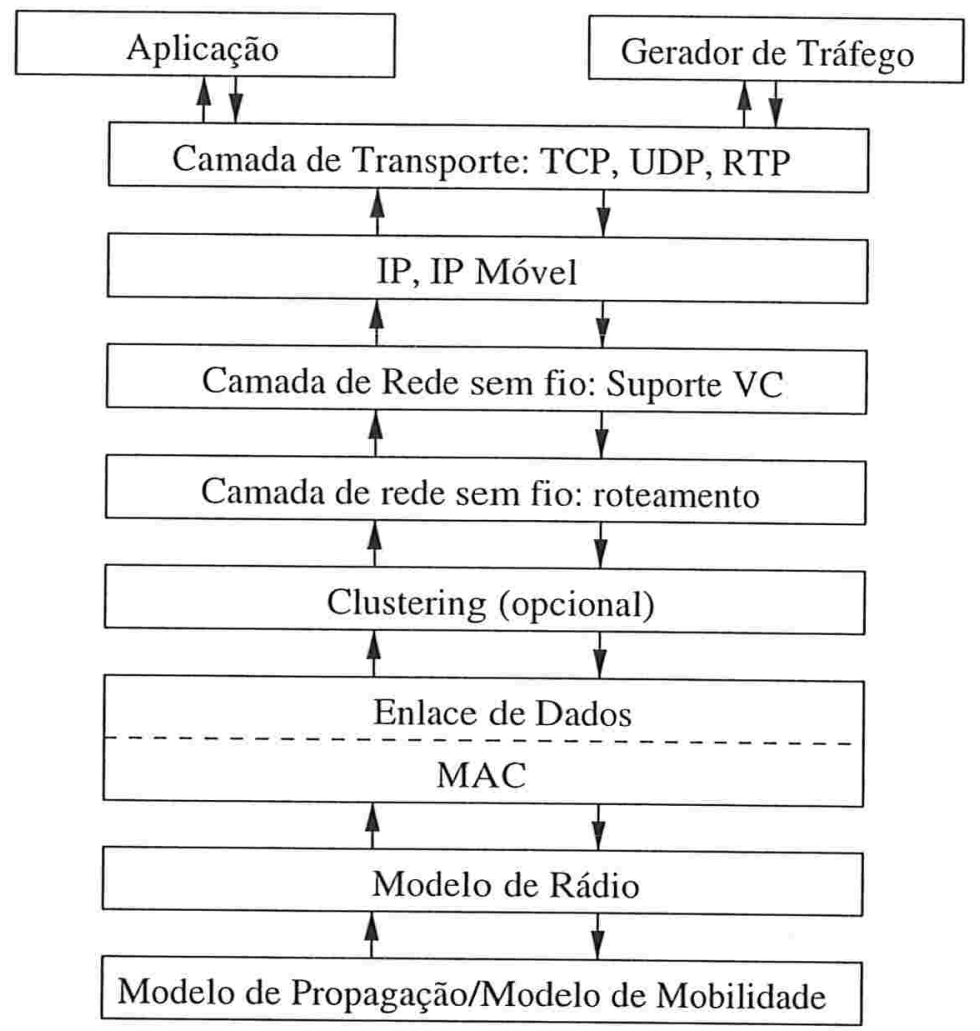

Figura 2.1: Arquitetura do GloMoSim

pecial ou através de uma especificação visual, utilizando para isso uma ferramenta chamada PAVE (PARSEC Visual Environment) que configura modelos de simulação usando componentes pré-definidos por GloMoSim. Esses mesmos mecanismos são utilizados também para especificar a topologia da rede e outras características da simulação.

O GloMoSim não permite a simulação de ambientes com as características necessárias ao funcionamento dos protocolos de entrega de mensagens: um ambiente híbrido com máquinas fixas e móveis se comunicando. Dessa forma, torna inviável sua utilização como base para este trabalho. A arquitetura do GloMoSim é baseada em ambientes paralelos o que aumentaria desnecessariamente a complexidade do projeto embora a utilização de ambientes paralelos busca aumentar o desempenho da simulação. Em nosso trabalho, o principal fator considerado é a redução do custo de programação de protocolos no que se refere ao projeto 
e implementação dos mesmos.

Uma característica interessante deste simulador é a existência de uma linguagem de alto nível para especificar a simulação de protocolos, bem como de uma ferramenta para a especificação visual de uma simulação.

Apesar de MobiCS utilizar a própria linguagem de programação Java para a especificação de simulações, os comandos utilizados são reduzidos e simples o suficiente para tornar a descrição de uma simulação fácil para o usuário. Dessa forma, a criação de uma linguagem para descrição de simulações em MobiCS não parece ter uma boa relação custo-benefício. Já a criação de uma ferramenta visual para a especificação da simulação no MobiCS parece interessante, mas a viabilidade de uma implementação precisa ser melhor avaliada.

\section{$2.4 \mathrm{Ns}$}

Ns $\left[\mathrm{BEF}^{+} 00\right]$ é um simulador baseado em eventos discretos, bastante flexível, que permite a simulação dos mais variados protocolos de rede. O modelo de programação de protocolos é divido em duas partes. As funções da simulação que estão diretamente ligadas ao desempenho e que mudam muito pouco depois de implementadas, como por exemplo o encaminhamento de pacotes por um roteador simulado, são construídas usando a linguagem $\mathrm{C}++$, já as funções diretamente ligadas à simulação, tais como definição, configuração e controle da simulação são feitas por uma linguagem de script chamada Tcl o que reduz significativamente o tempo gasto na construção de uma simulação.

Ns também permite emulação de rede, ou seja, torna possível a interação de uma rede simulada com uma rede real. Objetos simulados podem introduzir tráfego numa rede real e vice-versa.

Este simulador foi construído inicialmente sem suporte a simulação de protocolos para redes sem fio. Um outro projeto, chamado Monarch $\left[\mathrm{BMJ}^{+} 98\right]$, estendeu tal simulador para 
permitir a simulação de protocolos em redes sem fio. Esta extensão permite uma especificação explícita dos movimentos das unidades móveis através de parâmetros como coordenadas físicas e velocidade, permite também a geração de movimentos aleatórios baseados em padrões de movimento e tráfego definidos pelo usuário.

Uma característica deste simulador que dificultaria a sua escolha para este trabalho é o fato de que o módulo desenvolvido para dar suporte a mobilidade é direcionado para simular os detalhes de mais baixo nível da comunicação entre a unidade móvel e a estação-base, tais como recursos de radio, camada de enlace e controle de acesso ao meio.

De todas as características de Ns, a emulação de rede - possibilidade de interação entre nós de uma rede real e o simulador - se destaca, pois permite uma análise mais realista dos protocolos simulados na medida em que permite observar melhor o comportamento dos protocolos e suas implementações em sistemas reais. No contexto do nosso trabalho, não parece viável uma extensão do simulador MobiCS para permitir a interação com uma rede real já que o foco principal deste trabalho é facilitar a simulação de protocolos. $O$ tempo gasto com esta tarefa dificultaria de maneira significativa o alcance de nossas metas iniciais. 


\section{Capítulo 3}

\section{Protocolos para entrega de mensagens}

\section{em redes móveis}

Dentre os protocolos para computação móvel, existe uma classe específica na qual estamos interessados neste trabalho, que são os protocolos para entrega de mensagens unicast. Tais protocolos são adequados para serviços de consulta e assinatura. Este capítulo descreve os protocolos de entrega de mensagens encontrados em nossa pesquisa bibliográfica ${ }^{1}$.

Apesar de existirem inúmeros artigos sobre protocolos de comunicação [PMJ94, PRS96, AB93, RFV95, BS95, LL00, RBM00, BMSU01, TUSM94, RV98, CB95, JM96, MP99], nenhum deles trata de maneira específica a entrega de mensagens em redes móveis. Apenas alguns dos protocolos pareciam ter características semelhantes às do nosso trabalho [RBM00, BMSU01, TUSM94, RV98, CB95, JM96, MP99]. Após um estudo do funcionamento desses protocolos, foi possível adaptar apenas dois deles [JM96, MP99] que se adequavam melhor à entrega de mensagens. As seções 3.2, 3.3, 3.4 e 3.5 descrevem os protocolos escolhidos.

\footnotetext{
${ }^{1}$ As pesquisas foram feitas dentre os artigos dos últimos seis anos do livro Computer and Control Abstracts e em bibliotecas digitais na Internet.
} 


\subsection{Modelo do Sistema}

Em computação móvel, existem dois possíveis modelos de sistema: redes ad-hoc e redes móveis estruturadas [ML98]. Em redes ad-hoc, unidades móveis podem comunicar-se diretamente com outras unidades móveis que se encontram na sua área de cobertura ou utilizar outra unidade móvel para intermediar a comunicação. Em redes móveis estruturadas, a comunicação de uma unidade móvel com o restante do sistema é intermediada pela rede fixa.

O modelo de sistema adotado neste trabalho é o modelo de redes móveis estruturadas descrito por Bakre [BBIM93]. Esse modelo é dividido em duas partes: móvel e fixa. A porção fixa do sistema é composta por:

1. Servidores: máquinas responsáveis por armazenar as informações que podem ser consultadas e atualizadas pelos outros componentes do sistema. Estas máquinas encontramse conectadas fisicamente a uma rede fixa;

2. Estações de suporte a mobilidade (Mobile Support Stations - MSS): máquinas responsáveis por intermediar toda e qualquer comunicação das unidades móveis com o sistema. Também estão conectadas à rede fixa.

A porção móvel do sistema é composta apenas pelas unidades móveis (Mobile Hosts - Mh). Um Mh possui um identificador único em todo o sistema e pode encontrar-se em dois estados: ativo ou inativo. Quando ativo, o Mh pode enviar e receber informações do sistema. Quando encontra-se inativo, não pode estabelecer qualquer tipo de comunicação com o sistema.

A cada Mss está associado uma região geográfica chamada Célula. Toda unidade móvel localizada nesta região é de responsabilidade do Mss associado à Célula.

O conceito de célula é definido tanto por Rocha [Roc01] quanto na especificação do protocolo RDP [ESO00] como uma região geográfica atendida por uma única Mss. Esta nos 
parece ser uma limitação desnecessária do modelo. Um conceito para célula mais geral e que melhor se adequa ao modelo em questão é o de um conjunto de Mh's controlados por um dado Mss. Nada impede, por exemplo, que uma mesma região geográfica seja atendida por mais de um Mss para permitir um melhor balanceamento de carga, isso porque a idéia de migração no escopo destes trabalhos é simplesmente a mudança do Mss responsável por intermediar a comunicação do Mh com a rede fixa.

Um Mh utiliza o meio sem fio para comunicar-se com o sistema. Dessa forma, pode mudar de célula em qualquer instante de tempo. A esse fato dá-se o nome de migração. Ao entrar em uma nova célula, o Mh detecta uma mudança de localização e envia uma mensagem ao Mss responsável pela nova célula, a mensagem Greet. Essa mensagem carrega consigo a identificação do Mh e outras informações específicas a cada protocolo.

A figura $3.1^{2}$ mostra um cenário que exemplifica o modelo de sistema adotado. Os Mss's estão interligados pela rede fixa que proporciona uma alta taxa de transmissão. Também conectado à rede fixa estão os servidores que receberão consultas e atualizações. Os Mh's podem migrar de célula. No cenário, o $M h_{5}$, que inicialmente está na célula controlada pelo $M s s_{3}$, migra para a célula do $M s s_{4}$ e envia ao novo Mss a mensagem Greet com as informações necessárias para a migração ocorrer com sucesso.

As próximas seções descrevem os protocolos alvo deste trabalho. Em cada seção, estão descritas as principais suposições consideradas, a especificação das mensagens trocadas entre os componentes do sistema que servirá como parâmetro para uma abstração das mensagens comuns, as informações mantidas por cada protocolo e o funcionamento dos mesmos.

\footnotetext{
${ }^{2}$ Figura cedida por Ricardo Couto Antunes da Rocha [Roc01]
} 


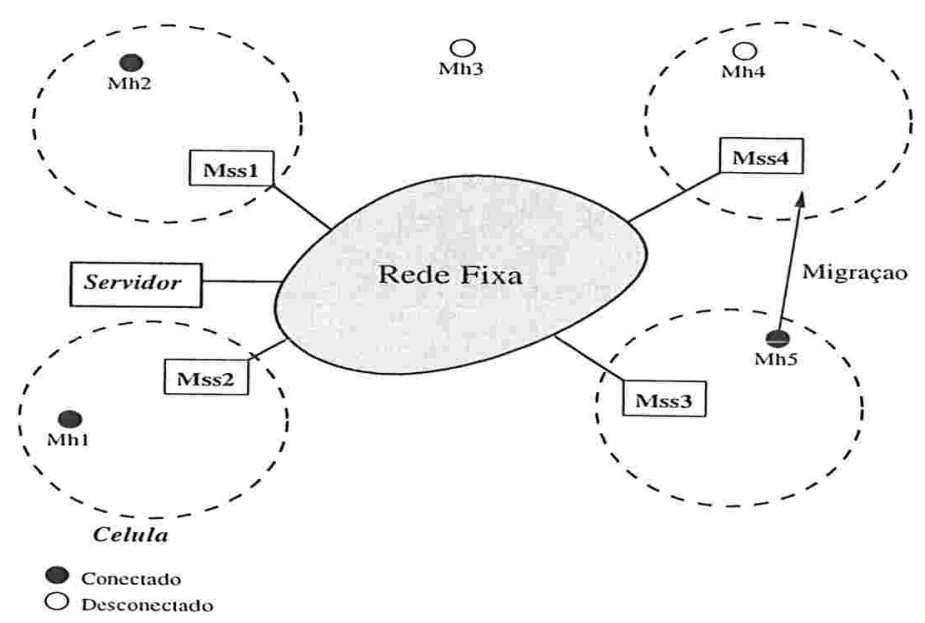

Figura 3.1: Modelo de Sistema

\subsection{RDP}

O RDP (Result Delivery Protocol) [ESO00] é um protocolo não orientado a conexão, adequado a serviços baseados no estilo requisição-resposta de comunicação que garante a entrega de mensagens a clientes móveis ${ }^{3}$. Foi desenvolvido para dar suporte a operações de consulta e assinatura dentro do projeto SIDAM [ESS $\left.{ }^{+} 00\right]$.

O RDP é baseado na noção de proxy. O proxy é um objeto que tem como principal função intermediar a comunicação entre o Mh e os servidores na rede fixa. Um proxy é criado no Mss responsável pela célula onde encontra-se o Mh no momento em que novas requisições são emitidas. No proxy são mantidas tanto as requisições pendentes como os resultados das requisições a serem repassados ao Mh. Este objeto permanece no sistema somente até que todas as requisições pendentes sejam atendidas. A partir de então, um novo proxy será criado na localização atual do Mh quando uma nova requisição for realizada. É importante ressaltar que, em qualquer instante, cada Mh está associado a um único proxy.

As suposições de modelo são importantes para a corretude no funcionamento, são elas:

\footnotetext{
${ }^{3} \mathrm{Um}$ estudo mais aprofundado deste protocolo e uma verificação formal do mesmo pode ser vista em [Tab02].
} 
1. Comunicação confiável entre $M s s^{\prime} s$;

2. Todos os Mss's são confiáveis;

3. Cada $M h$ está associado, em cada instante, a um único Mss;

4. Um Mh só deixa o sistema após confirmar o recebimento de todas mensagens;

5. O $M h$ detecta retransmissões;

6. Se um $M h$ está ativo, ele deve confirmar todas as mensagens recebidas do seu Mss corrente.

\subsubsection{Funcionamento}

O Mss responsável $\left(M s s_{\text {resp }}\right)$ por um Mh em um dado instante de tempo mantém armazenada uma referência para a localização do proxy associado ao Mh, chamada $p$ Ref. Sempre que um Mh envia uma requisição, seu $M s s_{\text {resp }}$ verifica o valor de pRef. Caso ele seja nulo, um novo proxy é criado. A requisição é então encaminhada ao proxy que se encarregará de repassá-la ao servidor. O servidor processa a requisição e devolve a resposta ao proxy que a encaminhará à atual localização do Mh.

No entanto, um Mh pode mudar sua localização antes que as respostas cheguem até ele. Portanto é importante que, ao ocorrer uma migração, ocorra também a transferência das informações relacionadas ao Mh do antigo para o novo Mss (processo de Hand-off). No processo de Hand-off do RDP, o valor de pRef é transferido para o novo Mss. Terminado o Hand-off, o novo $M s s_{\text {resp }}$ envia a mensagem update currentLoc ao proxy. Esta mensagem promoverá a atualização de uma variável do proxy, chamada currentLoc. Seu valor será atualizado com o endereço da nova localização do Mh. Atualizado o valor de currentLoc, o proxy encaminhará qualquer resultado pendente para a nova localização do $M$ h. 
Todos os resultados de requisições pendentes que chegam ao proxy são encaminhados ao $M s s_{\text {resp }}$ e repassados ao $\mathrm{Mh}$ através do meio sem fio. O Mh deverá confirmar o recebimento de todos os resultados o que permitirá ao proxy remover de requestList todas as requisições já atendidas. A confirmação do recebimento é essencial para a garantia de confiabilidade do protocolo.

A figura 3.2 ilustra o funcionamento do RDP. Neste exemplo, o Mh envia uma requisição ao servidor e, antes que receba o resultado, migra para a célula do $M s s_{1}$ e logo depois do $M s s_{2}$. Quando o $M s s_{0}$ (localização inicial do $\mathrm{Mh}$ ) recebe a requisição, verifica que pRef é nulo e cria um novo proxy. Este proxy repassa a requisição ao servidor que a processa e retorna um resultado. O resultado é então encaminhado ao proxy que repassa ao Mss cujo endereço encontra-se em currentLoc $\left(M s s_{1}\right)$. Junto com o resultado, segue del-pRef=true indicando ao Mh que a última requisição pendente foi atendida.

No entanto, antes que receba a resposta, o Mh migra para o $M s s_{2}$. A mensagem update currentLoc é enviada pelo $\mathrm{Mss}_{2}$ ao proxy, esse atualiza o valor de currentLoc e encaminha a resposta pendente para o $M s s_{2}$. A resposta é enviada pelo $M s s_{2}$ ao $\mathrm{Mh}$, que confirma o recebimento da resposta. Essa confirmação é repassada ao $M s s_{0}$ juntamente com del-proxy=true. Ao receber a mensagem de confirmação, o proxy é removido.

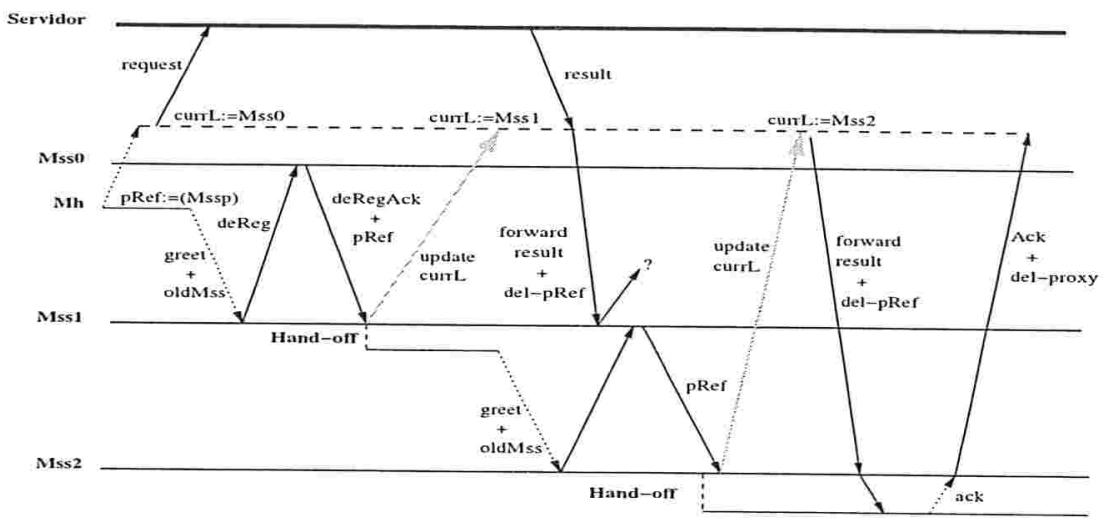

Figura 3.2: Cenário-Exemplo do RDP 


\subsubsection{Informações mantidas pelo sistema}

A seguir são listadas as informações mais importantes das entidades participantes:

1. No Proxy:

(a) currentLoc - Contém o endereço do atual $M s s_{\text {resp }}$ do Mh correspondente. É atualizada a cada migração do Mh.

(b) requestList - Lista de todas as requisições pendentes emitidas por um Mh.

2. No $M s s_{\text {resp }}$ :

(a) pRef - Referência para o atual proxy associado ao Mh. Permite que o proxy seja notificado de toda migração do Mh. Possui uma flag chamada RKpR(Ready to Kill $p R e f)$ que indica se o proxy encaminhou o resultado da última requisição pendente.

\subsubsection{Especificação das Mensagens}

A Tabela 3.1 especifica todas as possíveis mensagens trocadas entre duas máquinas (móveis ou fixas) do sistema.

\begin{tabular}{|c|c|l|}
\hline Mensagens & Participantes & Significado \\
\hline \hline greet & Mh $\rightarrow$ Mss & Mudança para a célula controlada pelo Mss \\
\hline request & Mh $\rightarrow$ Mss; Mss $\rightarrow$ Server & Envio de requisição a Server \\
\hline result & Server $\rightarrow$ Mss & Envio de resposta a Mss \\
\hline forwardRes & Mss $\rightarrow$ Mss & Envio do resultado ao atual $M$ ss $_{\text {resp }}$ \\
\hline forwardResWl & Mss $\rightarrow$ Mh & Envio do resultado ao Mh \\
\hline ack & Mh $\rightarrow$ Mss; Mss $\rightarrow$ Mss & Confirmação do recebimento de um resultado \\
\hline forwardAck & Mss $\rightarrow$ Mss & Encaminhamento de confirmação ao Proxy \\
\hline deReg & Mss $\rightarrow$ Mss & Cancelamento de registro de um Mh \\
\hline deRegAck & Mss $\rightarrow$ Mss & Confirmar o cancelamento do registro de um Mh \\
\hline updateCurrL & Mss $\rightarrow$ Mss & Atualizar a localização de um Mh no proxy \\
\hline
\end{tabular}

Tabela 3.1: Mensagens do RDP 


\subsection{SRDP}

O SRDP (Safe Result Delivery Protocol) [Dur01] é uma modificação do protocolo RDP que busca manter as mesmas garantias de confiabilidade na entrega sem que a confiabilidade dos Mss's e da rede fixa sejam críticas para o funcionamento do protocolo.

As suposições deste protocolo são:

1. Cada $M h$ está associado, em cada instante, a um único Mss;

2. O $M h$ detecta retransmissões.

3. Se um $M h$ está ativo, ele deve confirmar todas as mensagens recebidas do seu Mss corrente.

\subsubsection{Funcionamento}

Seu funcionamento é muito parecido com o do RDP diferenciando-se apenas em alguns detalhes que o torna tolerante a falhas na rede fixa. Uma característica peculiar desse protocolo é que, a cada migração, um novo proxy será criado caso existam requisições pendentes sendo que o proxy antigo pode ser coletado pelo sistema. Para garantir que requisições pendentes não sejam perdidas, cada Mh mantém localmente uma estrutura que implementa o padrão Memento [GHJV95]. Esta estrutura mantém todas as informações necessárias para a reconstrução do proxy. Dentre estas informações está a lista de requisições pendentes que são re-enviadas ao servidor logo após a criação do proxy.

A figura 3.3 exemplifica o funcionamento do SRDP. Ao chegar ao $M s s_{0}$, o Mh envia a mensagem greet. Essa mensagem é composta por todas as informações necessárias para a criação de um novo proxy. O proxy então re-envia a requisição pendente (request1) para o Servidor. Porém, antes que o Servidor envie o resultado desta requisição (result1) ao $M s s_{0}$, o Mh migra para a célula do $M s s_{1}$. A migração promove novamente o envio da mensagem greet 
ao novo Mss e a criação de um proxy com as requisições ainda não atendidas (request1). A requisição pendente é então novamente enviada. No entanto, o Mh mais uma vez migra antes que receba o resultado. Somente na célula do $M s s_{2}$ o Mh permanece tempo suficiente para receber o resultado, confirmar o seu recebimento e evitar o re-envio da mesma requisição. A manutenção das informações necessárias à reconstrução do proxy, tal como as requisições ainda não atendidas, é que tornam tal protocolo tolerante a falhas de um Mss do sistema. Todos os outros proxies antigos criados em Mss's anteriores devem ser coletados pelo sistema utilizando algoritmos de coleta de lixo.

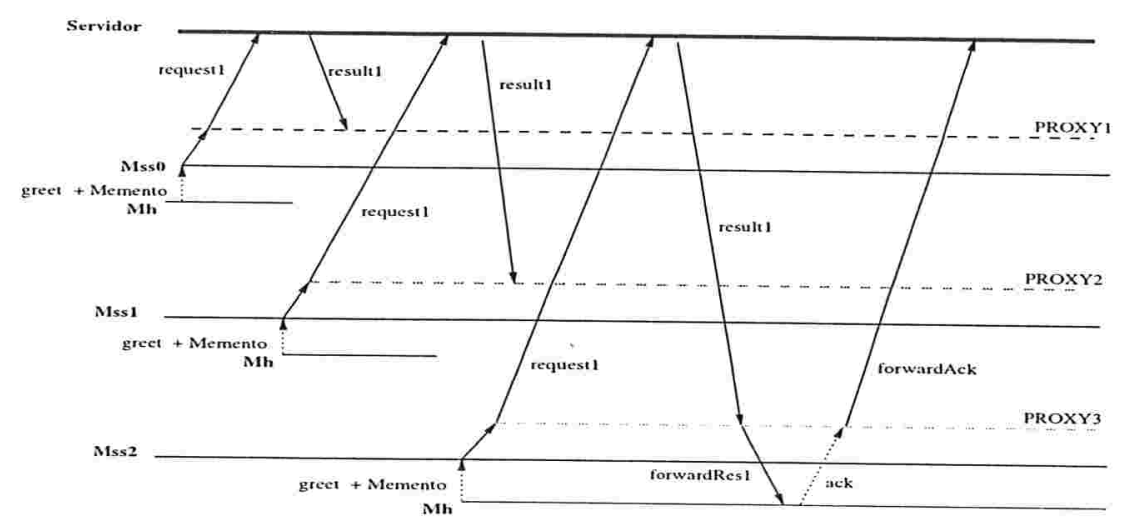

Figura 3.3: Cenário-Exemplo do SRDP

\subsubsection{Informações mantidas pelo sistema}

1. Proxy - Representante do Mh na rede fixa.

2. Memento - Estrutura mantida pelo Mh que contém as informações mínimas necessárias para a reconstrução do proxy.

\subsubsection{Especificação das Mensagens}

A Tabela 3.2 especifica as mensagens do protocolo SRDP e seus respectivos significados. 


\begin{tabular}{|c|c|l|}
\hline Mensagens & Participantes & Significado \\
\hline \hline greet & Mh $\rightarrow$ Mss & Mudança para a célula controlada pelo Mss \\
\hline request & Mh $\rightarrow$ Mss; Mss $\rightarrow$ Server & Envio de requisição a Server \\
\hline result & Server $\rightarrow$ Mss & Envio de resposta a Mss \\
\hline forwardResWl & Mss $\rightarrow$ Mh & Envio do resultado ao Mh \\
\hline ack & Mh $\rightarrow$ Mss; Mss $\rightarrow$ Mss & Confirmação do recebimento de um resultado \\
\hline forwardAck & Mss $\rightarrow$ Server & Encaminhamento de confirmação para Server \\
\hline
\end{tabular}

Tabela 3.2: Mensagens do SRDP

\subsection{Mobile IP Adaptado}

O Mobile IP [JM96] é um protocolo desenvolvido pela IETF (Internet Engineering Task Force), o mais importante órgão de padronização de protocolos para a Internet. Este protocolo foi projetado para tornar possível o roteamento de pacotes IP's a unidades móveis utilizando-se de um endereço IP fixo.

O protocolo IP tem a função de traçar um caminho de uma rede a outra (roteamento) e assim permitir a comunicação entre computadores. Isso só é possível com um esquema de endereçamento hierárquico no qual atribui-se um endereço a cada computador da rede. Através desse endereço é possível localizar um computador e a rede na qual está localizado.

A mobilidade torna esse esquema de endereçamento, da forma como foi concebido, inviável, pois uma unidade móvel pode mudar de sub-rede várias vezes, o que torna a mobilidade não transparente à localização. Para buscar uma solução, um grupo de estudos da IETF criou o protocolo Mobile IP.

Tomando como referência a arquitetura baseada em camadas do padrão TCP/IP, o Mobile IP é um protocolo da camada de rede. Uma adaptação do protocolo para a camada de aplicação é proposta neste trabalho como forma de permitir uma comparação com os demais protocolos. 


\subsubsection{Funcionamento}

No Mobile IP, um computador móvel possui dois endereços: o endereço fixo que qualquer máquina possui numa rede IP, também chamado de home address e um endereço que muda a cada migração da unidade móvel, chamado care-of address. A rede fixa é composta por dois tipos de estações-base: o home agent que é a estação de origem de um Mh e o foreign agent que é a estação responsável por um Mh em um dado instante de tempo, mas que não é sua estação de origem.

Quando um pacote é direcionado a uma unidade móvel, utiliza-se o home address como endereço de destino. O pacote então chega na rede de destino e é recebido pelo home agent. Ao receber um pacote cujo destino é um Mh que não se encontra na rede local, o home agent, através de sua tabela de roteamento, encaminha o pacote ao atual foreign agent do Mh. O foreign agent por sua vez, utilizará o care-of address do Mh para repassar-lhe o pacote.

Isso só é possivel porque a cada migração do Mh, ocorre uma atualização da sua localização no home agent que agora deverá encaminhar qualquer pacote para o novo foreign agent daquele Mh.

A adaptação do Mobile IP para o contexto deste trabalho resume-se a tratar mensagens (requisições e resultados) como pacotes. Os home agents e foreign agents correspondem, respectivamente, ao Mss de origem e ao Mss Atual. O funcionamento é semelhante, o Mh envia uma requisição a um servidor que retorna uma resposta ao Mss de origem e este, através de sua tabela de rotas, encaminha a mensagem a atual localização do $\mathrm{Mh}\left(M s s_{\text {resp }}\right)$. A migração do Mh implica na atualização da tabela de rotas do seu Mss de origem.

A diferença entre o Mobile IP e o RDP está na forma de controlar as respostas a serem entregues ao Mh. No Mobile IP, esta função é desempenhada pelo Mss de origem durante todo o processo de comunicação do Mh independente da sua localização, ou seja, um único nó da rede fixa é responsável por desempenhar o papel de redirecionador de mensagens, já 
no caso do RDP essa função pode ser desempenhada por qualquer nó da rede, pois sempre que todas as requisições pendentes são atendidas, a função de redirecionador de mensagens é delegada ao atual Mss onde se encontra o Mh.

A figura 3.4 ilustra a mecânica do protocolo Mobile IP adaptado. Neste cenário, o Mss de origem do Mh corresponde ao $M s s_{1}$. Como nos cenários dos protocolos anteriores, o Mh, que encontra-se inicialmente na célula controlada pelo $M s s_{0}$, envia uma nova requisição. Juntamente, segue o endereço do seu Mss de origem. O servidor processará esta requisição e retornará o resultado ao Mss de origem. Antes que receba o resultado, o Mh migra para a célula do $M s s_{1}$, por coincidência o seu Mss de origem. A seguir, migra mais uma vez, agora para a célula do $\mathrm{Mss}_{2}$. Neste momento, uma mensagem greet é enviada ao novo Mss contendo o endereço do Mss de origem. Ao recebê-la , o $M s s_{2}$ envia uma mensagem updateCurrL ao Mss de origem para que este atualize a localização do Mh no sistema. O Mss de origem então atualiza a localização do $\mathrm{Mh}$ e envia qualquer resultado pendente que esteja armazenado ao $M s s_{\text {resp. }}$. O Mh, enfim, recebe o resultado e envia uma mensagem de confirmação. Esta confirmação é repassada ao Mss de origem promovendo a remoção dos resultados pendentes.

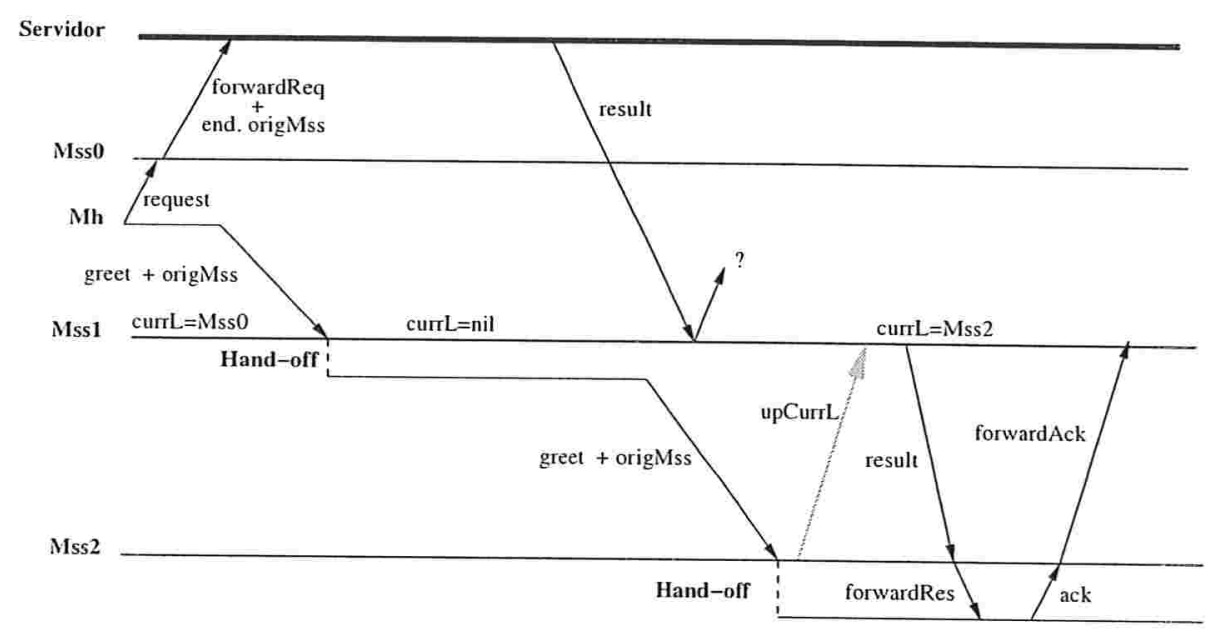

Figura 3.4: Cenário-Exemplo do Mobile IP 


\subsubsection{Informações mantidas pelo sistema}

1. localDests - Contém o endereço de todos os Mh's que, em um determinado instante, estão na rede local mas que pertencem a outra rede. Guarda também o endereço dos Mss de origem de cada um desses Mh's.

2. tLocal - Armazena o endereço de todos os Mh's pertencentes à rede local e suas localizações atuais.

\subsubsection{Especificação das Mensagens}

A Tabela 3.3 mostra as mensagens trocadas entre duas máquinas do sistema.

\begin{tabular}{|c|c|l|}
\hline Mensagens & Participantes & Significado \\
\hline \hline greet & Mh $\rightarrow$ Mss & Mudança para a célula controlada pelo Mss \\
\hline request & Mh $\rightarrow$ Mss; Mss $\rightarrow$ Server & Envio de requisição a Server \\
\hline result & Server $\rightarrow$ Mss & Envio de resposta a Mss \\
\hline forwardRes & Mss $\rightarrow$ Mss & Envio do resultado ao atual $M s s_{\text {resp }}$ \\
\hline forwardResWl & Mss $\rightarrow$ Mh & Envio do resultado ao Mh \\
\hline updateCurrL & Mss $\rightarrow$ Mss & Atualizar a localização de um Mh no $M s s_{\text {orig }}$ \\
\hline ack & Mh $\rightarrow$ Mss; Mss $\rightarrow$ Mss & Confirmação do recebimento de um resultado \\
\hline forwardAck & Mss $\rightarrow$ Server & Encaminhamento de confirmação para Server \\
\hline
\end{tabular}

Tabela 3.3: Mensagens do MobileIP

\subsection{Snapshot}

O nome snapshot refere-se a um algoritmo de entrega de mensagens confiável que surgiu da adaptação da idéia de snapshots distribuídos descrita por Lamport [CL85]. O objetivo de algoritmos de snapshot (cuja a tradução literal é foto instantânea) é coletar o estado local dos canais e das máquinas para construir a consistência global do sistema. A técnica de entrega confiável de mensagens descrita por Murphy [MP99] utiliza as mesmas idéias. Porém, ao 
invés de distribuir o estado do sistema, é distribuída a mensagem a ser entregue. As seções a seguir descrevem o funcionamento do algoritmo.

Também visando permitir a inserção deste protocolo no contexto do trabalho foi realizada uma adaptação do seu funcionamento, como poderá ser visto na seção seguinte.

O modelo de sistema para este algoritmo possui algumas particularidades em relação ao modelo descrito inicialmente. Os canais de comunicação entre os nós são direcionados e possuem um estado associado: ABERTO ou VERIFICADO. Os canais em cada nó são classificados em canais de entrada e canais de saída. A migração dos Mh's, também chamados de agentes, deve atender a estrutura de canais do sistema. Assume-se que a rede é estruturada como um grafo conexo (existe um caminho entre dois quaisquer nós, mas não necessariamente um canal entre eles) e direcionado. Geograficamente, esta suposição é válida, já que num sistema real as células não são vizinhas de todas as outras.

\subsubsection{Funcionamento}

Inicialmente, todos os canais do sistema encontram-se no estado ABERTO. Quando um Mss recebe uma mensagem, o canal de entrada através do qual ele recebeu essa mensagem tem seu estado mudado para VERIFICADO, o que indica que qualquer Mh que siga a rota desse canal já recebeu a mensagem. Quando um Mss recebe pela primeira vez uma mensagem, ele armazena a mesma e tenta entregá-la ao Mh de destino caso este encontre-se na célula local. Num passo atômico, a mensagem é propagada por todos os canais de saída. Para todo Mh que chega por um canal no estado ABERTO, o Mss tenta entregar as mensagens armazenadas caso seja o destino da mensagem. Assim que todos os canais de entrada de um Mss encontram-se no estado VERIFICADO para uma determinada mensagem, essa é removida do buffer de mensagens, pois não há mais como um Mh chegar a este Mss sem ter recebido a mensagem. Desta forma, garante-se que um Mh, em algum momento, receberá a 
mensagem, mesmo em situações de intensa migração.

Como forma de permitir uma comparação com os protocolos anteriores, a seção 3.5.3 especifica as mensagens necessárias ao funcionamento deste protocolo. Além disso, a figura 3.5 mostra um simples exemplo de topologia de rede utilizado como base para a construção do cenário da figura 3.6.

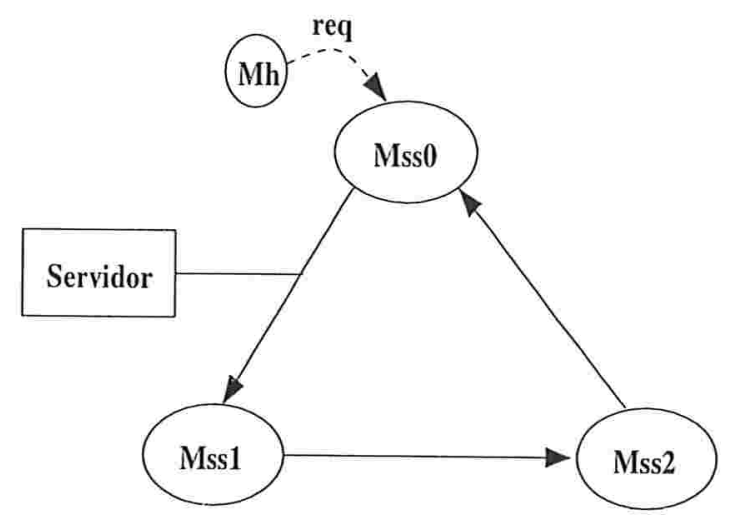

Figura 3.5: Exemplo de topologia de rede adequado para o protocolo Snapshot

Neste cenário, o Mh emite uma requisição. O $M s s_{0}$ repassa a requisição ao servidor que a processará e retornará um resultado ao Mss responsável pela requisição $\left(M s s_{0}\right)$. Sempre que um Mh migra, ele envia uma mensagem greet ao novo Mss. O novo Mss responde com uma mensagem chamada dereg que promove a remoção do registro do Mh no antigo Mss. No exemplo em questão, esse processo de handoff ocorre duas vezes: Entre o $M s s_{0}$ e o $M s s_{1}$ e entre o $M s s_{1}$ e o $M s s_{2}$.

Ao receber o resultado, o $M s s_{0}$ verifica se o Mh encontra-se na célula local. Caso encontrese, repassa o resultado diretamente para o Mh. Caso contrário, envia tal mensagem pelos canais de saída. Neste exemplo, pelo canal que liga o $M s s_{0}$ ao $M s s_{1}$. Logo a seguir, verifica se a mensagem já trafegou por todos os canais de entrada. Em caso afirmativo, remove-a do conjunto de mensagens pendentes. O mesmo ocorre quando o resultado é recebido pelo $M s s_{1}$. O processo termina quando todos os Mss's do sistema receberam o resultado o que 
garantirá que, em algum instante, o Mh receberá o resultado e confirmará o seu recebimento.

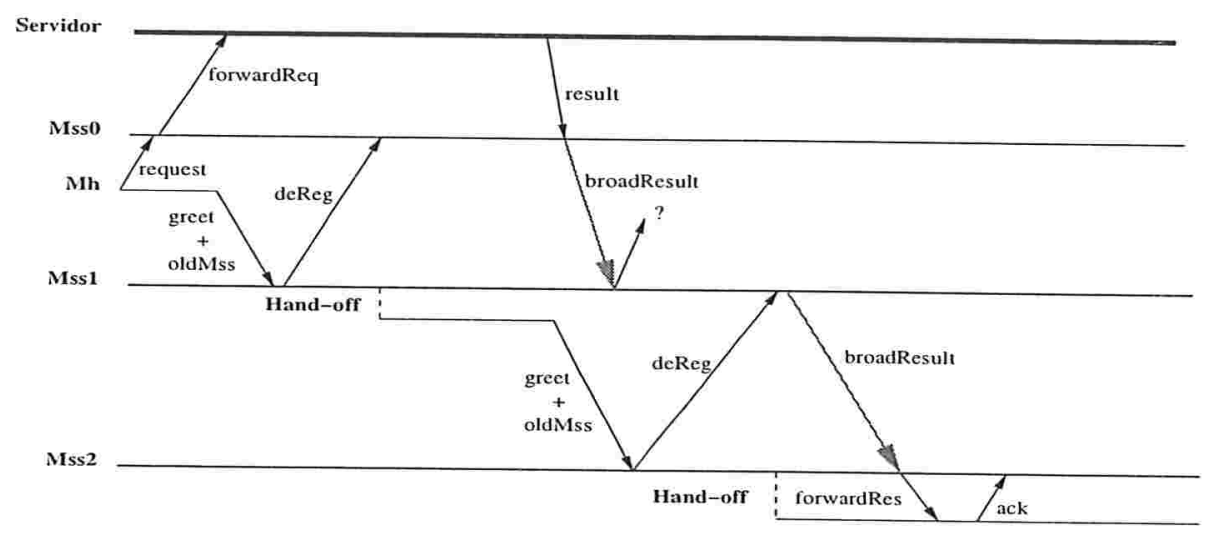

Figura 3.6: Cenário-Exemplo do Snapshot

\subsubsection{Informações mantidas pelo sistema}

Cada Mss possui um vetor de objetos representando todas as suas conexões (canais) com os outros Mss's do sistema. Os atributos de cada objeto são:

1. Nome ou endereço do Mss ao qual está conectado;

2. Vetor de estados do canal com o identificador de todas as mensagens recebidas;

3. Tipo de canal
(a) Entrada
(b) Saída

Cada Mss possui também um buffer com as mensagens não entregues indexado pelo endereço dos Mh's destino. 


\subsubsection{Especificação das Mensagens}

\begin{tabular}{|c|c|l|}
\hline Mensagens & Participantes & Significado \\
\hline \hline greet & Mh $\rightarrow$ Mss & Mudança para a célula controlada pelo Mss \\
\hline request & Mh $\rightarrow$ Mss; Mss $\rightarrow$ Server & Envio de requisição a Server \\
\hline result & Servidor $\rightarrow$ Mss & Envio do resultado de uma requisição \\
\hline broadResult & Mss $\rightarrow$ Mss & Envio do resultado através dos canais de saída \\
\hline forwardResWl & Mss $\rightarrow$ Mh & Envio do resultado ao Mh \\
\hline ack & Mh $\rightarrow$ Mss & Confirmação do recebimento de um resultado \\
\hline deReg & Mss $\rightarrow$ Mss & Cancelamento de registro de um Mh \\
\hline
\end{tabular}

Tabela 3.4: Mensagens do Snapshot

\subsection{Análise Comparativa}

Esta seção analisa de maneira resumida o funcionamento dos protocolos descritos nas seções anteriores. A validação das conclusões só será feita mediante simulação.

Todos os protocolos aqui descritos garantem, de alguma forma, a entrega de mensagens a estações móveis. Segundo Murphy [MP99], os protocolos podem ser classificados em duas categorias quanto à forma de entrega da mensagem: protocolos de entrega por encaminhamento e entrega por broadcast. Os protocolos RDP, SRDP e Mobile IP encontram-se na primeira categoria, enquanto o protocolo de Snapshot na segunda. Analisando por este ponto de vista, em situações de pouca mobilidade nas quais a estação móvel permanece tempo suficiente para receber uma mensagem, os protocolos de encaminhamento mostram-se mais eficientes, pois produzem um menor tráfego levando a um menor congestionamento da rede.

Analisando os protocolos de encaminhamento, é possível observar que o RDP possui requisitos de confiabilidade muito fortes o que compromete a sua aplicação. No entanto, permite o balanceamento de carga do sistema, pois quando todas as requisições pendentes são atendidas, o proxy é removido e recriado na atual localização do Mh e dessa forma há 
uma diminuição na indireção causada muitas vezes pelo fato de o Mh encontrar-se em uma outra célula que não a do proxy.

O SRDP mostra avanços no que diz respeito aos requisitos de confiabilidade do sistema, pois garante a entrega de mensagens a unidades móveis mesmo em situações de falha da rede fixa ou do Mss. Porém, para situações em que a velocidade de migração é elevada e a migração muito intensa, o protocolo pode levar a uma sobrecarga do sistema, pois, nesse caso, as requisições pendentes seriam refeitas a cada migração do $\mathrm{Mh}$, gerando muita informação repetida.

O Mobile IP comparado aos outros dois protocolos de encaminhamento possui um balanceamento de carga menor, pois a função de representante do Mh na rede fixa que era dada ao proxy nos outros protocolos é de responsabilidade do Mss que controla a célula de origem do Mh, chamado ss $_{\text {orig. }}$. Toda mensagem destinada ao Mh é encaminhada ao Mss orig o que não permite um balanceamento de carga, pois concentra num ponto fixo do sistema todo o processo de comunicação com o Mh. Além disso, o Mobile IP possui requisitos de confiabilidade ainda mais fortes, pois em caso de falha do $M s s_{\text {orig }}$ não é mais possível estabelecer comunicação com o Mh.

Ao contrário dos outros protocolos, o Snapshot utiliza uma técnica que envolve contactar cada Mss do sistema pelo menos uma vez, gerando tráfego comparável a um broadcast. Porém para situações em que o Mh muda seu representante na rede fixa (proxy ou Mss $s_{\text {orig }}$ ) com uma alta freqüência, os protocolos de encaminhamento possivelmente terão um menor desempenho pois produzem um alto custo adicional em situações de alta mobilidade dos Mh's. Dessa forma, o snapshot é adequado para situações em que o Mh movimenta-se com alta freqüência.

Como forma de permitir a implementação dos protocolos, tomou-se como referência o modelo de especificação e programação de protocolos descrito por Bhatti [BHSC98]. Nesse 
modelo, um protocolo é composto por módulos de funcionalidade bem definida chamados micro-protocolos. Os micro-protocolos interagem através de eventos (mensagens ou eventos de tempo) e são compostos por um conjunto de métodos, chamados manipuladores de eventos que são executados em resposta à ocorrência de um evento.

Uma organização em micro-protocolos adequada ao ambiente de computação móvel, foi utilizada por Acharya [AB93]. Esta organização separa as funcionalidades distintas de um protocolo tanto no que se refere à mobilidade como ao meio de comunicação. São três os micro-protocolos desta organização:

- Wired: Controla todas as mensagens trocadas entre estações fixas.

- Wireless: Responsável pelas mensagens trocadas através do meio sem fio.

- Handoff: Responsável pelas mensagens que controlam a migração de estações móveis.

Este modelo permitiu a criação da tabela 3.6 que classifica os protocolos e possibilita uma fatoração inicial das mensagens comuns.

\begin{tabular}{|c|c|l|}
\hline Wired & wireless & Handoff \\
\hline \hline result & ack & greet \\
\hline broadResult(Ss) & SystemRequest & deReg(R,Ss) \\
\hline forwardRes(R,M) & forwardResWl & deRegAck(R) \\
\hline forwardAck(R,S,M) & & updateCurrL(R,M) \\
\hline ServerRequest & & \\
\hline
\end{tabular}

Legenda:

$\mathrm{R} \rightarrow \mathrm{RDP}$
$\mathrm{S} \rightarrow \mathrm{SRDP}$
$\mathrm{M} \rightarrow$ Mobile IP
$\mathrm{Ss} \rightarrow$ Snapshot

Tabela 3.5: Classificação das mensagens quanto aos Micro-protocolos 
Seguindo essa organização, a tabela 3.6 mostra todas as mensagens dos protocolos aqui descritos. As mensagens result, ack, ServerRequest, SystemRequest e forwardResWl são comuns a todos os protocolos. A mensagem greet, apesar de estar presente em todos os protocolos, possui parâmetros diferenciados para cada um. As mensagens restantes são específicas de alguns protocolos como mostrado na tabela. 


\section{Capítulo 4}

\section{A Biblioteca}

\subsection{Motivação}

Segundo Eric Gamma et al. [GHJV95], "um arcabouço é um conjunto de classes cooperantes que compõem um projeto reutilizável para uma classe específica de software. Pré-define os parâmetros de projeto para que, o programador/projetista da aplicação, possa concentrar-se nas particularidades da aplicação".

Uma importante contribuição do uso de arcabouços na construção de aplicações é a possibilidade de reutilização tanto de projeto quanto de implementação. Dessa forma, o uso de arcabouços é adequado a situações em que o desenvolvimento de várias aplicações similares é feito com freqüência. Nesses casos, o arcabouço ocasionará uma significativa diminuição no tempo necessário para construção de uma aplicação e, por conseguinte, uma redução nos custos de desenvolvimento.

Existem várias dimensões de classificação de arcabouços. Uma classificação segundo Fayad [FSJ99], refere-se às técnicas utilizadas para estendê-los:

- Arcabouços caixa-branca: Baseiam-se em características das linguagens tais como 
herança e amarração dinâmica visando alcançar extensibilidade. A funcionalidade existente é reutilizada e estendida por herança das classes-base do arcabouço e reescrevendo métodos usando padrões como Template [GHJV95].

- Arcabouços caixa-preta: A extensibilidade é obtida através da definição de interfaces para componentes que podem ser ligados ao arcabouço através da composição de objetos.

- Arcabouços caixa-cinza: Um passo intermediário entre os dois tipos de arcabouço anteriores. Um bom arcabouço caixa-cinza possui flexibilidade e extensibilidade suficiente e também a habilidade de ocultar informações desnecessárias do desenvolvedor da aplicação.

O uso de arcabouços no desenvolvimento de aplicações, quando realizado corretamente, pode aumentar a produtividade do programador e diminuir o esforço de desenvolvimento. As principais vantagens de se utilizar arcabouços, segundo Fayad [FSJ99] e Mattson [Mat96], são:

- Uma redução significativa na quantidade de linhas de código necessárias ao desenvolvimento de uma aplicação;

- O código contido no arcabouço é menos passível de erros, pois foi verificado pelo seu desenvolvedor;

- A re-utilização de projeto e não só de código permite que o usuário do arcabouço adquira mais experiência no que se refere ao projeto de aplicações;

- Permite que aspectos de eficiência não considerados no projeto de muitas aplicações sejam aplicados pelos desenvolvedores do arcabouço; 
- Apresenta um modelo claro e flexível do domínio;

Este capítulo descreve a arquitetura de uma biblioteca que estende o MobiCS de forma a torná-lo um arcabouço caixa-cinza. A decisão de tornar o MobiCS um arcabouço caixa-cinza visa abstrair funcionalidades mapeadas a partir de uma observação criteriosa do domínio de protocolos de entrega de mensagens e assim simplificar o uso do simulador sem reduzir a flexibilidade e extensibilidade pré-existente.

\subsection{Programação de protocolos no MobiCS}

O modelo de programação de protocolos do simulador MobiCS é baseado no conceito de micro-protocolos [BHSC98]. Os micro-protocolos são módulos que implementam uma funcionalidade bem definida do protocolo como, por exemplo, um micro-protocolo responsável por todos os eventos relacionados ao processo de hand-off de um Mh. Este conceito permite uma composição horizontal de protocolos, na medida em que um protocolo é um conjunto de micro-protocolos que se comunicam através de eventos. Um evento corresponde a qualquer ocorrência que promova a invocação de um micro-protocolo como, por exemplo, o envio de uma mensagem. Essa composição horizontal permite a experimentação de diversas alternativas

Esses micro-protocolos possuem uma interface que corresponde a todos os eventos que podem ser gerados e tratados pelos mesmos. Isto permite a interação entre os micro-protocolos como pode ser visto na figura $4.1^{1}$.

Cada micro-protocolo é composto por um conjunto de métodos responsáveis por executar todas as operações necessárias ao correto tratamento da ocorrência de um evento, chamados manipuladores de eventos. Para cada mensagem de um protocolo, deve existir um método manipulador de evento correspondente.

\footnotetext{
${ }^{1}$ Figura cedida por Ricardo Couto Antunes da Rocha [Roc01]
} 


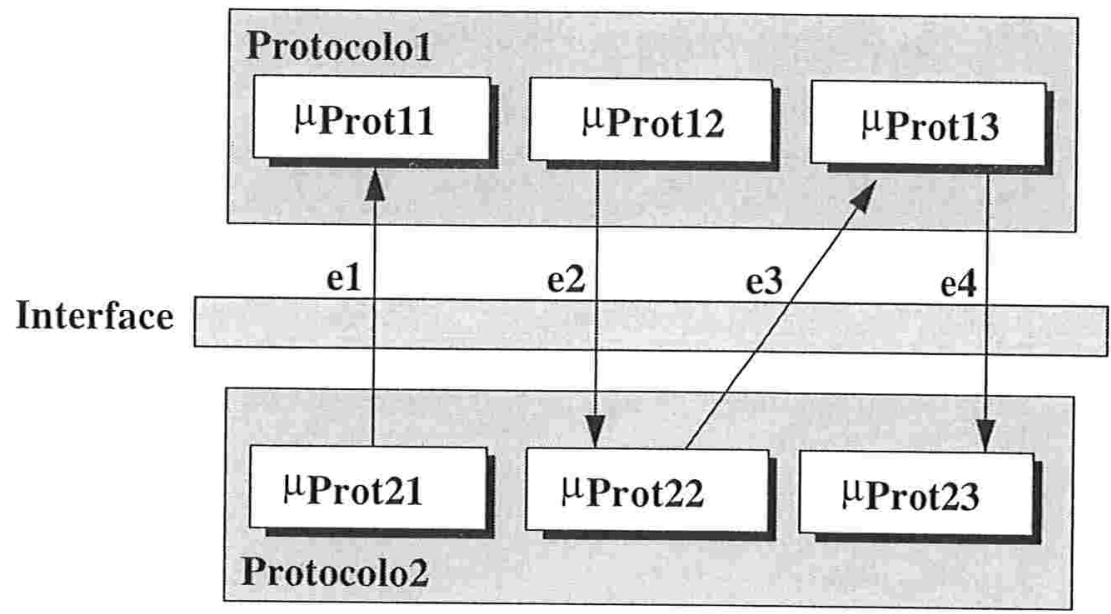

Figura 4.1: Interação entre micro-protocolos

O MobiCS é implementado como uma biblioteca Java contendo um conjunto de classes necessárias para a simulação e programação de protocolos. As principais classes do simulador relacionadas ao trabalho do programador são:

1. Element - Implementação de um elemento de rede abstrato que contém toda a funcionalidade comum a todos os elementos de rede. Oculta de suas subclasses toda informação sobre simulação. Possui duas subclasses fundamentais: Mh - mantendo toda a implementação específica de um Mh tais como mobilidade e desconexão - e Mss, com detalhes específicos de um Mss simulado².

2. Protocol - Classe base para implementação de um protocolo de rede. Basicamente define um método para envio de mensagens a um destinatário. Suas subclasses são: MssProtocol e MhProtocol.

3. Message - Define os atributos e a implementação básica de toda mensagem. Toda mensagem a ser enviada ou tratada por um protocolo deve ser declarada como uma

\footnotetext{
${ }^{2}$ MobiCS não provê uma classe com detalhes específicos de um Servidor. A classe Mss é utilizada como classe-base para este tipo de máquina simulada.
} 
subclasse de Message. Define uma interface mínima de uma mensagem. Declara alguns atributos existentes em qualquer mensagem, como destinatários e remetente.

4. Simulation - Classe abstrata com as principais interfaces para definição de uma simulação.

Numa simulação, o usuário estende este conjunto de classes básicas do simulador para definir o protocolo, as mensagens, as máquinas simuladas e o modelo de simulação desejado. Para implementar um protocolo, primeiramente o usuário deve criar um conjunto de subclasses de Message para especificar todas as mensagens trocadas entre as máquinas simuladas. A seguir, o usuário deve estender as subclasses de Protocol: MssProtocol para implementar cada um dos tipos de máquinas simuladas da rede fixa ou MhProtocol para as máquinas simuladas da rede móvel;Essas subclasses do usuário devem conter, para cada mensagem, um método que permita às máquinas simuladas tratar o seu recebimento.

A seguir, o usuário deve construir as simulações para avaliação do protocolo. O MobiCS possui dois modelos de simulação. A escolha do modelo de simulação depende do tipo de teste que se deseja realizar:

- Simulação Determinística - Implementa uma simulação na qual o simulador executa um roteiro que descreve exatamente os eventos ocorridos no sistema. Utilizado para testar as situações críticas em que o protocolo poderia eventualmente falhar. Neste caso, o usuário deve estender a classe DetermSimulation e especificar, em um método chamado script(), todos os passos da simulação tais como migração de Mh's, envio de mensagens e modificação do estado de ativação dos Mh's. Veja na figura $4.2 \mathrm{um}$ exemplo de simulação determinística. 


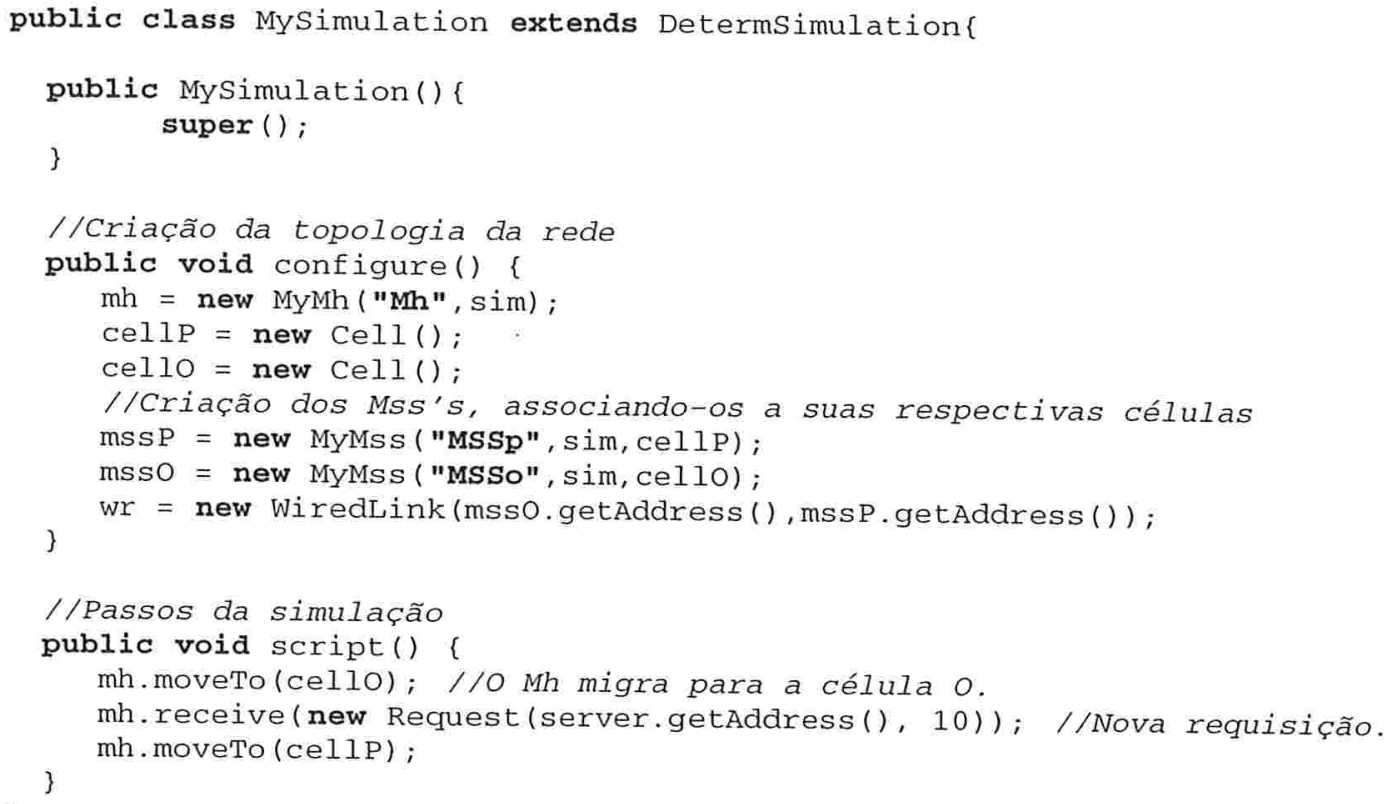

Figura 4.2: Simulação Determinística

- Simulação Estocástica - Submete o protocolo a uma simulação estocástica seguindo um padrão de comportamento dos elementos simulados definido pelo usuário. Esse padrão de comportamento leva em consideração parâmetros como probabilidade de migração e probabilidade de desconexão de um Mh. Este modelo de simulação é adequado para testar o desempenho do protocolo em situações mais realistas. O usuário deve estender a classe StochSimulation e definir padrões de comportamento dos elementos simulados tais como probabilidade de migração dos Mh's e probabilidades de desconexão e re-conexão. Um exemplo de simulação estocástica pode ser visto na figura 4.3 . 


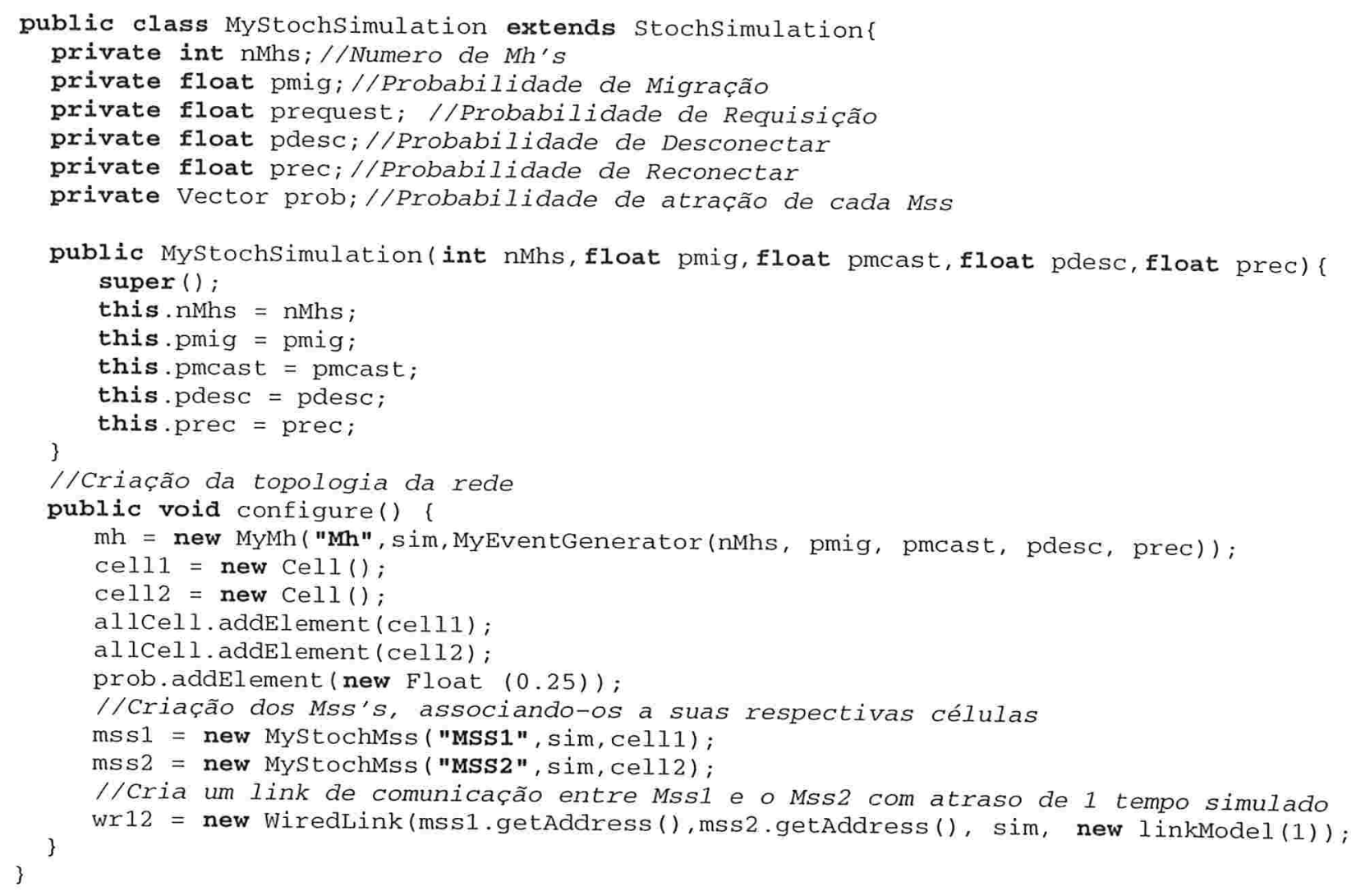

Figura 4.3: Simulação Estocástica

\subsubsection{Implementação do RDP no MobiCS}

O RDP será tomado como exemplo de utilização do MobiCS para a simulação de protocolos. Para implementá-lo, são necessários os seguintes passos:

1. Implementar todas as mensagens trocadas entre as máquinas simuladas como subclasse de Message e especificar todos os parâmetros de cada mensagem. São um total de 12 mensagens como pode ser visto na Tabela 4.1.

2. Implementar o protocolo propriamente dito. Criar uma subclasse de Protocol para cada um dos três tipos de máquina simulada: Servidores, Mss's e Mh's. Os Servidores 


\begin{tabular}{|c|c|l|}
\hline Mensagens & Participantes & Significado \\
\hline \hline greet & Mh $\rightarrow$ Mss & Mudança para a célula controlada por Mss \\
\hline UserRequest & Usuário $\rightarrow$ Mh & Início de uma requisição pelo usuário \\
\hline SystemRequest & Mh $\rightarrow$ Mss; & Envio de requisição ao Sistema \\
\hline ServerRequest & Mss $\rightarrow$ Server & Repasse da requisição ao Servidor \\
\hline result & Server $\rightarrow$ Mss & Envio de resposta a Mss \\
\hline forwardRes & Mss $\rightarrow$ Mss & Envio do resultado ao atual $M s s_{\text {resp }}$ \\
\hline forwardResWl & Mss $\rightarrow$ Mh & Envio do resultado ao Mh \\
\hline ack & Mh $\rightarrow$ Mss; Mss $\rightarrow$ Mss & Confirmação do recebimento de um resultado \\
\hline forwardAck & Mss $\rightarrow$ Mss & Encaminhamento de confirmação ao Proxy \\
\hline deReg & Mss $\rightarrow$ Mss & Cancelamento de registro de um Mh \\
\hline deRegAck & Mss $\rightarrow$ Mss & Confirmar o cancelamento de registro de um Mh \\
\hline updateCurrL & Mss $\rightarrow$ Mss & Atualizar a localização de um Mh no proxy \\
\hline
\end{tabular}

Tabela 4.1: Mensagens do RDP

e Mss's que são máquinas fixas do sistema devem estender a subclasse MssProtocol. Já os Mh's estendem a subclasse MhProtocol. Cada uma das novas subclasses deverá conter os manipuladores para as mensagens por ele tratadas. Esses manipuladores nada mais são que métodos contendo o tratamento a ser dado ao recebimento de uma dada mensagem. O nome dos métodos manipuladores devem ser da forma: when + $<$ Nome_da_Mensagem $>^{3}$. Por exemplo, na figura 4.4 é mostrado o método de manipulação da mensagem request.

\footnotetext{
${ }^{3}$ A obrigatoriedade deste formato para o nome dos métodos é devido a utilização da técnica de reflexão, oferecida pela linguagem Java, que permite ao simulador detectar o método a ser executado em cada situação.
} 


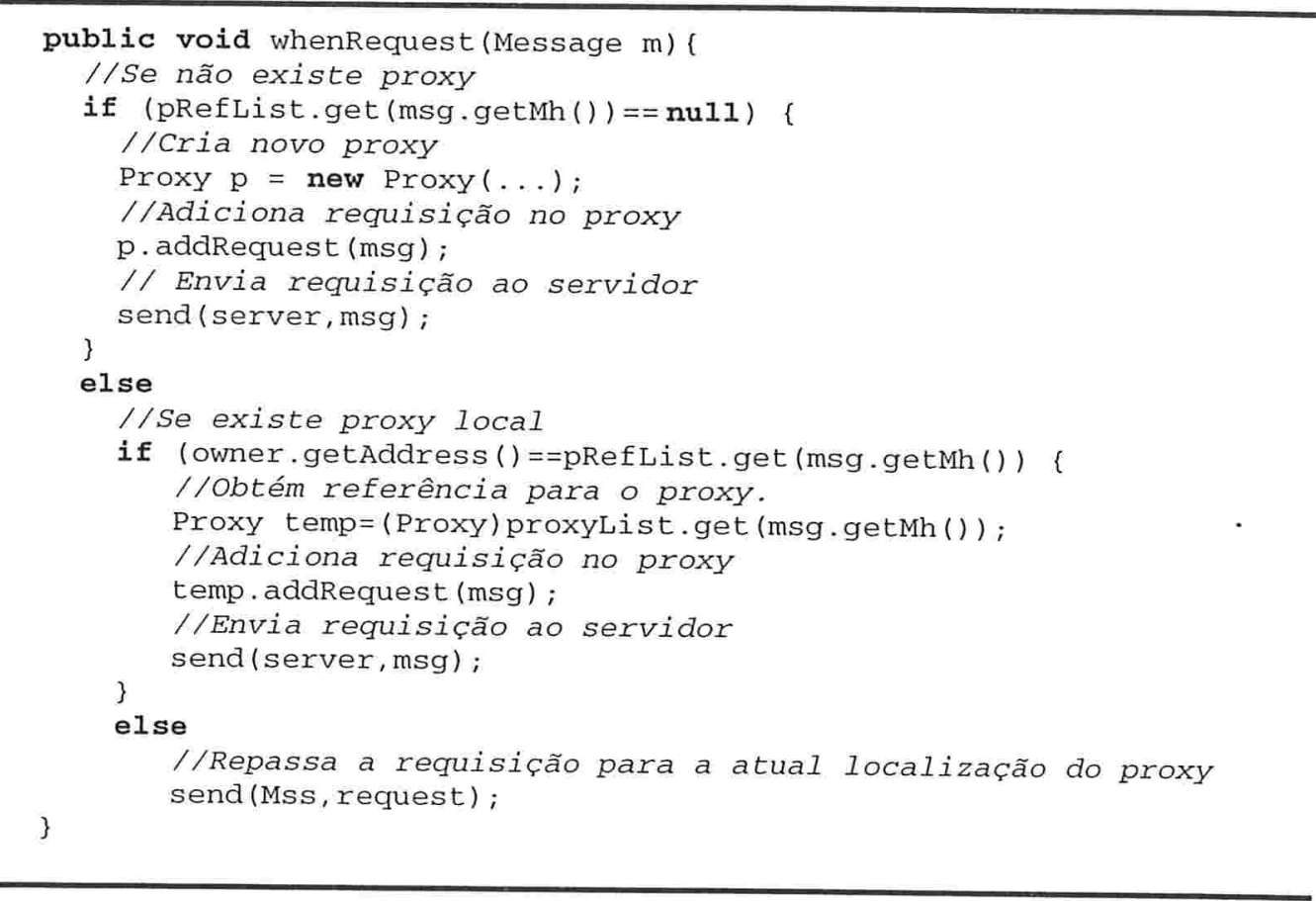

Figura 4.4: Método whenRequest() da subclasse de MssProtocol

3. Criar as máquinas simuladas. Para as unidades móveis, deve ser criada uma subclasse de Mh. Esta subclasse deve ser associada, através da operação attach() do simulador, a uma instância da subclasse de MhProtocol construída no passo anterior. O mesmo deve ser feito para os Mss's e Servidores que deverão estender a classe Mss e associá-las à subclasse de MssProtocol também construída no passo anterior. Como pode ser visto na figura 4.5 .

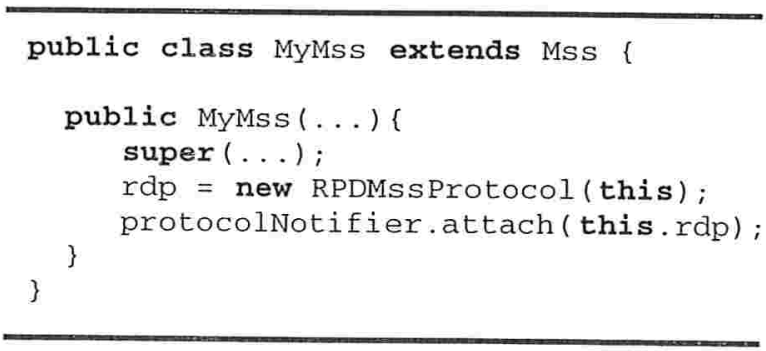

Figura 4.5: Exemplo de Mss 
Essa associação, entre as máquinas simuladas e uma instância do protocolo, permite que o simulador possa identificar e executar os métodos manipuladores correspondentes a qualquer evento tratável por um elemento simulado.

4. Construir a simulação propriamente dita. Na simulação são criadas várias instâncias das classes construídas no passo anterior. É desenhada a topologia da rede e os eventos que devem ocorrer na simulação são especificados de maneira determinística ou estocástica como explicado anteriormente.

5. Criar uma aplicação Java. Essa aplicação deve gerar uma instância da simulação construída no passo anterior e executar a operação start() para que a simulação seja realizada.

\subsection{Modificações realizadas no MobiCS}

A implementação de protocolos que necessitam enviar informações específicas a cada mudança de célula não é possível no modelo original de MobiCS. A única informação enviada ao novo Mss através da mensagem Greet é o endereço do antigo Mss. Tal deficiência não permitia a implementação de protocolos como o Mobile IP no qual o Mh a cada migração envia o endereço do Mss de origem. Foi realizada uma modificação no simulador de maneira que cada protocolo agora deverá definir sua própria mensagem de migração. A mensagem Greet do simulador não possui mais funcionalidade. Isso dá ao usuário uma maior flexibilidade na definição dos parâmetros da mensagem que deve ser enviada pelo Mh ao Mss na ocorrência de uma migração. Para realizar essa alteração, foi necessária a re-implementação do método onMove() da classe Mh. Esse método, responsável por efetivar a mudança de célula do Mh dispara um método chamado onGreet() que deve ser implementado por suas subclasses. Esse método deve retornar a mensagem de migração a ser enviada ao novo Mss. 
O modelo de sistema adotado pelo protocolo Snapshot insere uma nova propriedade não levada em consideração pelo simulador MobiCS que é a limitação na migração dos Mh's entre as células do sistema. No modelo original, um Mh pode migrar de uma célula para qualquer outra do sistema. Porém, como se pode observar numa rede real bem como na descrição do modelo de sistema do protocolo Snapshot, os Mh's têm sua mobilidade limitada aos Mss's vizinhos. É interessante observar que o modelo de sistema do protocolo Snapshot parece mais realista perante ao adotado por MobiCS já que numa rede real um Mh tem sua migração limitada às células vizinhas à que se encontra em um dado instante. Para permitir a criação de vizinhanças entre células, foi incorporada ao simulador a classe Neighbor para estabelecimento de vizinhanças. Sempre que um Mh tenta migrar para uma dada célula, o simulador verifica se é uma célula vizinha. Caso não seja, é gerada uma exceção que impede a ocorrência da migração.

O protocolo SRDP supõe a possibilidade de falha de um Mss como pode ser visto no capítulo 3. Porém, no simulador MobiCS, a simulação de falha de um Mss não é possível. Para prover essa funcionalidade, foram implementados os métodos available() e unavailable() na classe Mss que permite desativar toda a comunicação do Mss tanto com a rede fixa quanto com a rede móvel.

Outra modificação realizada foi a definição da classe Server para a criação dos servidores em uma simulação. Com a criação desta classe, o servidor que, no modelo original de MobiCS, era uma instância da classe Mss passa a possuir apenas as funcionalidades específicas de um Servidor. Com essa nova classe, o modelo de implementação de protocolos se torna mais condizente com a realidade na medida em que atribui ao servidor suas funcionalidades específicas. As instâncias da classe Server, diferentemente das instâncias de Mss, possuem interface de comunicação somente com a rede fixa e não são associados a uma célula do sistema. 
No MobiCS, a mensagem de broadcast era distribuída a todos os elementos de rede conectados pelo meio com fio. Com a separação do servidor como elemento que apenas responde a requisições, a mensagem de broadcast é distribuída apenas entre os Mss's do sistema.

No modelo original de MobiCS, a definição dos eventos de migração e envio de requisição é totalmente dependente do protocolo que está sendo simulado, já que são necessárias a incorporação de instâncias das mensagens na definição do evento. Por exemplo, a definição do evento de requisição é mostrada na figura 4.6.

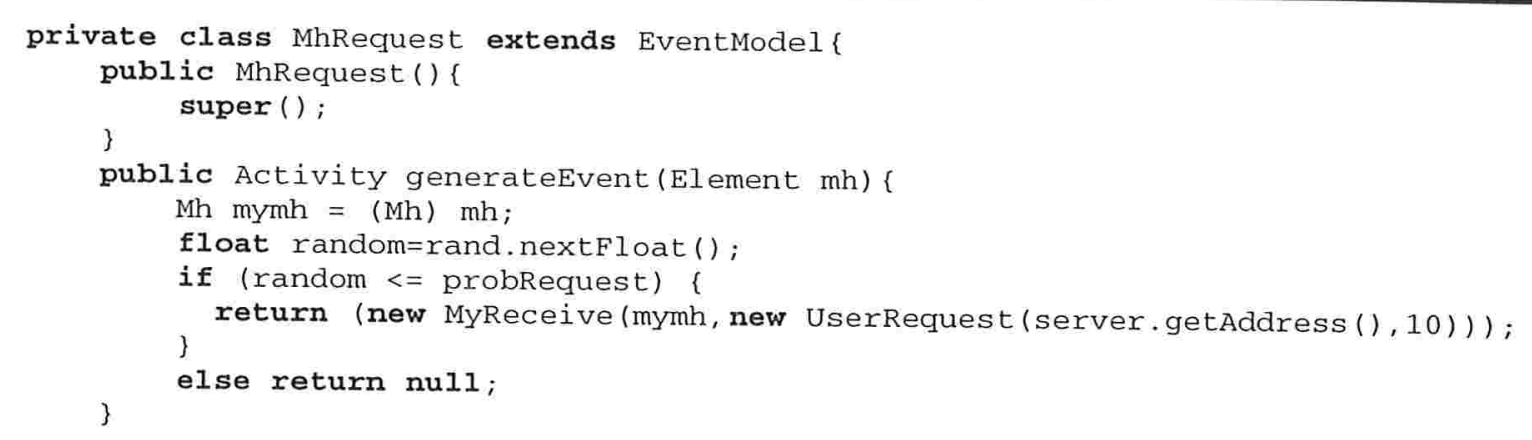

Figura 4.6: Modelo de evento para Requisições no RDP

Como se pode observar, o próprio evento é responsável por gerar a requisição (UserRequest). Como forma de retirar qualquer vínculo da biblioteca com o código do protocolo criado pelo usuário, foram necessárias algumas alterações no simulador de forma que o Mh passe a ser responsável por gerar a mensagem de requisição. Foi criada uma nova classe no simulador, chamada StochMh, que possui as mesmas funcionalidades da classe Mh acrescentando o método abstrato onRequest() que retornará a requisição enviada pelo Mh. Esse método deve ser implementado pelas subclasses de StochMh definidas pelo usuário. Optou-se por definir uma nova classe ao invés de definir o método onRequest() diretamente na classe Mh porque a geração da mensagem de requisição na simulação determinística é explicitamente 
definida nos passos da simulação, sendo que a geração da requisição como responsabilidade do Mh só se faz necessária no modo estocástico.

\subsection{Arquitetura do Sistema}

MobiCS segue o modelo de arcabouço caixa-branca deixando a cargo do programador muitos detalhes que eventualmente poderiam estar implementados no próprio arcabouço, o que diminuiria o esforço de programação.

A biblioteca desenvolvida neste trabalho contém um conjunto de classes Java que estendem a funcionalidade de MobiCS, tornando-o um arcabouço caixa-cinza, reduzindo o trabalho do usuário na descrição de um novo protocolo, mas com a preocupação de não reduzir a flexibilidade e extensibilidade já existentes no simulador.

É fundamental ressaltar que este trabalho foi direcionado a facilitar a implementação de protocolos - suas mensagens e manipuladores - e não à simulação do mesmo. Isso porque a maior dificuldade está exatamente na implementação do protocolo e não na sua simulação (Criação das máquinas simuladas, construção da topologia de rede e descrição dos eventos simulados). É na implementação do protocolo que está concentrada a maior parte do trabalho manual e, principalmente, intelectual.

Na subseção 4.2.1, foram descritos todos os passos necessários à implementação do protocolo RDP. Como se pode observar, apesar das facilidades que o simulador MobiCS traz para a simulação de protocolos, todo esse processo ainda é muito custoso, principalmente no que se refere à implementação das mensagens e dos seus respectivos manipuladores.

Com o estudo realizado no Capítulo 3, constatou-se algumas semelhanças entre os protocolos de entrega de mensagens: As mensagens trocadas entre os elementos simulados e o tratamento que as máquinas simuladas dão ao recebimento dessas mensagens. Toda essa semelhança entre os protocolos desta classe levam a uma re-escrita de código que pode ser 
facilmente evitada com a extensão do MobiCS. A funcionalidade comum foi então reunida em uma biblioteca para permitir a sua reutilização na simulação de protocolos.

Como pode ser visto na Tabela 3.6 do Capítulo 3, as mensagens Request, Result, Ack e forwardRes são comuns - em termos de funcionalidade - a todos os protocolos descritos. Tais mensagens foram implementadas na biblioteca de maneira que o programador não precise redefini-las em cada simulação.

Para ilustrar a nova estruturação proveniente da criação da biblioteca, as figuras 4.7 e 4.8 mostram, respectivamente, como se dá a implementação de um protocolo antes e depois da sua existência.

A implementação convencional de um protocolo no MobiCS possui a estrutura mostrada na figura 4.7. Um protocolo é construído instanciando ou estendendo classes do simulador.

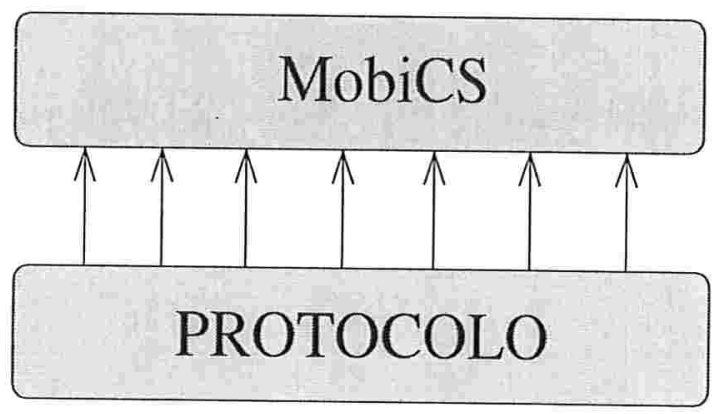

Figura 4.7: Interação padrão com o MobiCS

Com a criação da biblioteca, uma nova camada é inserida na estrutura, agora o código dos protocolos estende ou instancia classes da biblioteca que por sua vez estende e instancia classes do simulador. A figura 4.8 ilustra a nova estrutura.

A biblioteca contém a definição prévia de todas as mensagens comuns à classe de protocolos como pode ser visto na figura 4.9. Tais mensagens foram especificadas de maneira a permitir a sua re-utilização. Existe a possibilidade de que algumas mensagens tenham que ser definidas pelo programador de protocolos, pois existem mensagens específicas de cada protocolo que não são implementadas pela biblioteca. Por exemplo, o RDP possui uma men- 


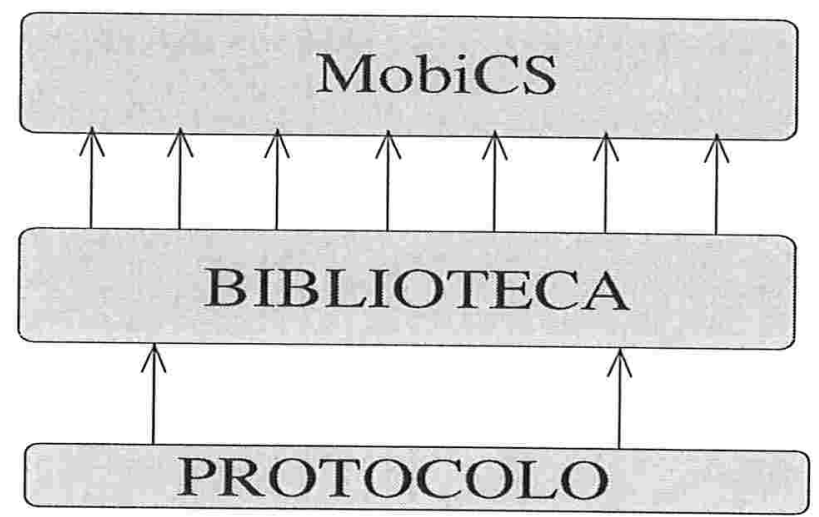

Figura 4.8: Novo modelo de interação

sagem chamada deRegAck que serve para informar ao Mss, responsável pela célula onde encontra-se o Mh, a localização do proxy no sistema. Essa mensagem só existe neste protocolo, portanto não parece adequado colocar sua implementação na biblioteca por ser uma mensagem bem específica. Caso o programador decida implementar o protocolo RDP ou qualquer outro protocolo que utilize essa mensagem ou qualquer outra em particular, terá que criar uma nova classe, subclasse de Message, contendo todos os parâmetros que compõem a nova mensagem.

Partindo da idéia de que o envio de uma mensagem é um evento e que um protocolo deve tratar cada um desses eventos, a biblioteca define os métodos manipuladores de todas as mensagens citadas anteriormente.

No diagrama da figura 4.9 estão destacados os três componentes que formam a nova estrutura de programação de protocolos: $\mathrm{O} \mathrm{MobiCS}^{4}$, a Biblioteca e o Protocolo.

\subsubsection{Componentes do sistema}

A biblioteca é composta por Mensagens: Classes Java que definem as mensagens trocadas entre as máquinas simuladas e Manipuladores: Classes Java contendo a implementação

\footnotetext{
${ }^{4} \mathrm{O}$ diagrama destaca apenas as classes do MobiCS que devem ser estendidas pelo programador de protocolos.
} 


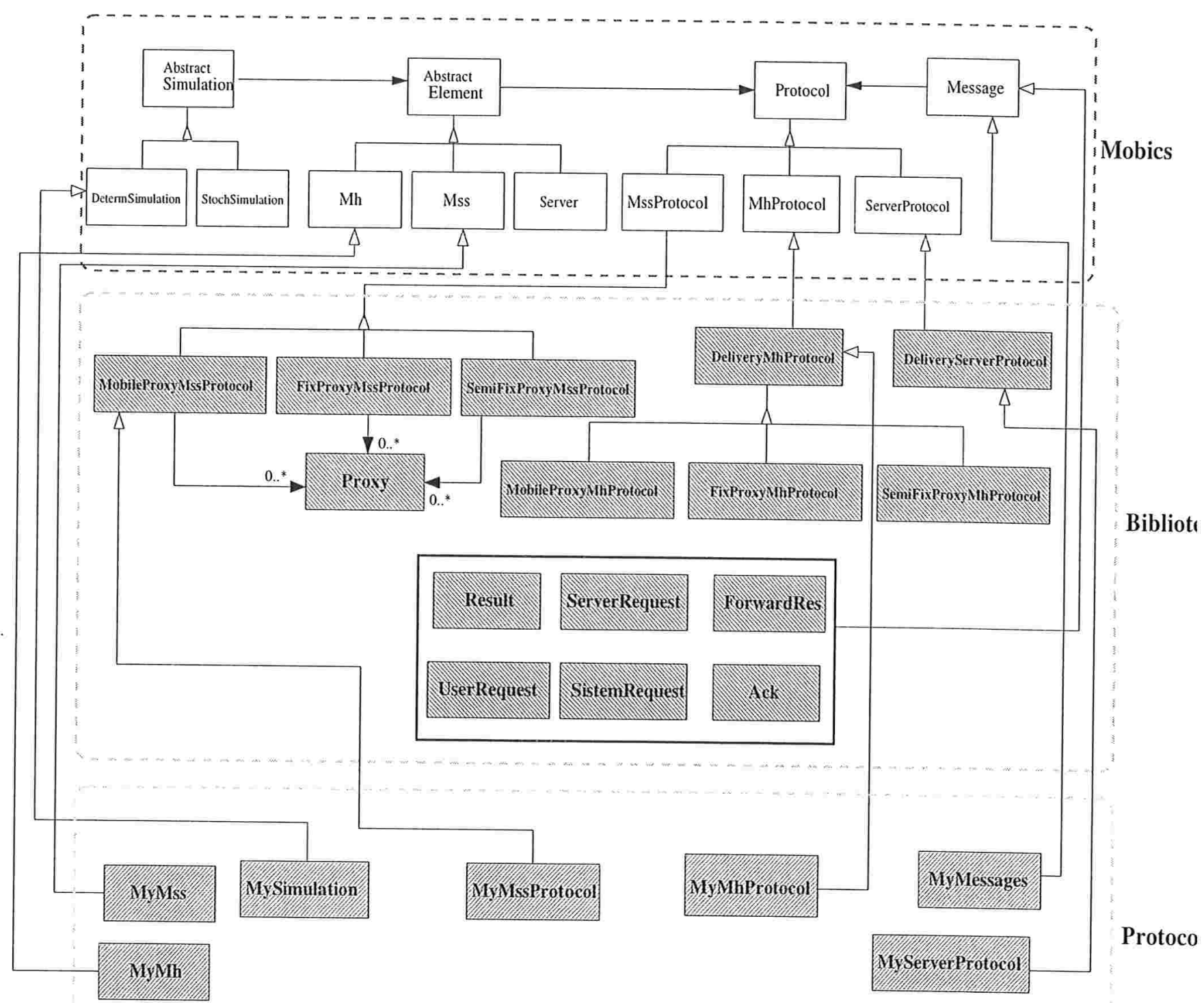

Figura 4.9: Diagrama de Classes

dos métodos que tratam o envio de mensagens. A seguir, é mostrada uma descrição mais detalhada dos componentes da biblioteca: 


\section{Manipuladores}

Contém todos os métodos que realizam o tratamento de eventos. Tais métodos correspondem àquelas mensagens cujo tratamento é semelhante para todo o conjunto de protocolos. Foram definidos manipuladores para os três tipos de elemento de rede. São eles:

1. Para o Mss - A partir da observação dos protocolos de entrega de mensagens, resultaram três classes contendo os métodos manipuladores para as mensagens comuns mapeadas. Essa divisão deve-se ao fato de que a reação dos protocolos é função direta do comportamento do proxy no sistema. As classes são:

(a) FixProxyMssProtocol - Conjunto de métodos manipuladores dos Mss's utilizados em protocolos que mantêm uma localização fixa para o proxy. Utilizado para a implementação do protocolo Mobile IP. Possui uma estrutura que armazena a lista de todos os Mh's pertencentes a outra rede juntamente com o endereço do Mss da rede de origem e uma lista do Mh's pertencentes à rede local com sua atual localização. Nesta classe, estão definidos os seguintes manipuladores:

i. whenAck - Envia uma mensagem de confirmação ao Mss de origem do Mh;

ii. whenFowardRes - Repassa o resultado ao Mh;

iii. whenResult - Se o Mh estiver na célula local, repassa-lhe o resultado. Caso contrário, envia para a atual localização do $\mathrm{Mh}$;

iv. whenSystemRequest - Cria um identificador para a requisição e a envia ao servidor.

(b) SemiFixProxyMssProtocol - Métodos manipuladores dos Mss's utilizados em protocolos que mantém uma localização "semi-fixa" para o proxy. Utilizado para a implementação do protocolo RDP. Mantém uma lista de todos os proxy's dos Mh's que realizaram requisiçôes num instante em que se encontravam na célula local e 
outra lista com o endereço do Mss onde se encontra o proxy dos Mh's locais. Esta classe define os seguintes manipuladores:

i. whenAck - Remove do Proxy a requisição e o resultado correspondente à confirmação recebida;

ii. whenFowardRes - Repassa o resultado ao Mh;

iii. whenResult - Adiciona o resultado ao proxy, repassa-o ao Mh caso ele encontrese na célula local. Caso contrário, repassa a atual localização do Mh;

iv. whenSystemRequest - Caso não exista proxy para o Mh, um é criado, a requisição é adicionada ao proxy e enviada ao servidor. Se já existe um proxy e este é local, a requisição é adicionada ao proxy e repassada ao servidor. Caso contrário, a requisição é repassada a atual localização do proxy.

(c) MobileProxyMssProtcol - Métodos manipuladores dos Mss's utilizados em protocolos que mantém uma localização móvel para o proxy. Utilizado para a implementação do protocolo SRDP. Essa classe possui uma lista de todos os proxy's dos Mh's locais. Estão definidos os seguintes manipuladores:

i. whenAck - Remove do Proxy a requisição e o resultado correspondente à confirmação recebida;

ii. whenResult - Adiciona o resultado ao proxy, repassa-o ao $\mathrm{Mh}$;

iii. whenSystemRequest - Cria um identificador para a requisição que é adicionada ao proxy e enviada ao servidor.

2. Para o Mh - Foram definidas também classes para o Mh nas três possibilidades mapeadas. Essas classes possuem manipuladores para tratar o envio de uma nova requisição e o recebimento de um resultado. As classes mapeadas são: 
(a) FixProxyMhProtocol - Armazena o endereço do Mss que desempenhará a função de proxy durante todo o funcionamento do protocolo;

(b) SemiFixProxyMhProtocol - Além dos métodos manipuladores do Mh para o proxy "semi-fixo", contém o endereço da atual localização do proxy no sistema;

(c) MobileProxyMhProtcol - Guarda uma estrutura contendo todas as informações necessárias à reconstrução do proxy a cada migração.

3. Para o Servidor - Classe DeliveryServerProtocol contém os métodos manipuladores para o elemento de rede Servidor. Ele define o método manipulador para a mensagem ServerRequest responsável por tratar o recebimento de uma requisição retornando o resultado da mesma.

\section{Mensagens}

Essas classes especificam a estrutura interna das mensagens. Uma mensagem no MobiCS é representada por uma classe, subclasse de Message, que contém a especificação dos campos da mensagem e os métodos de acesso a esses campos. As classes aqui definidas, são importantes no reuso de projeto pois especificam as mensagens comuns à classe de protocolos. As mensagens incluídas na biblioteca são:

1. Ack - Confirmação de que o Mh recebeu o resultado de uma requisição. Contém o endereço do Mh que confirmou o recebimento e um identificador da requisição correspondente ao resultado que está sendo confirmado;

2. ForwardRes - Encaminhamento do resultado de uma requisição;

3. SystemRequest - Requisição enviada de um Mh ao seu Mss responsável. Contém o endereço do Mh que enviou a requisição, o endereço do servidor de destino e o conteúdo da requisição; 
4. ServerRequest - Requisição encaminhada do MSS ao servidor. Composta pelo endereço do Mss responsável pela requisição, por um identificador e pela requisição enviada do Mh ao Mss;

5. UserRequest - Requisição feita por uma aplicação ao Mh. Contém a requisição e o endereço do servidor de destino;

6. Result - Resultado da requisição. É formada pelo conteúdo resultante do processamento de uma requisição, pelo endereço do Mh ao qual se destina este resultado e por um identificador associado a cada resultado.

Na subseção 4.4.2, serão descritos alguns detalhes considerados na implementação das mensagens da biblioteca.

\section{Proxy}

O estudo da mecânica de funcionamento dos protocolos de entrega de mensagens mostra que o Proxy, como representante do Mh na rede fixa, pode ser considerado comum à classe de protocolos, apesar de não aparecer de maneira explícita em alguns protocolos. No Mobile IP, por exemplo, a função de Proxy é exercida pelo Mss de origem.

Partindo da premissa de que o proxy pode ser considerado parte integrante dos protocolos de entrega de mensagens, a biblioteca também incorpora a classe Proxy contendo a implementação das funcionalidades básicas para essa classe de protocolos. Ele possui uma lista de requisições pendentes e um lista com os resultados ainda não entregues ao Mh de destino. Na sua criação, especifica-se o endereço do Mh correspondente e a atual localização do Mh na rede fixa. Essa classe permite ainda que se adicione e remova atributos não declarados, fazendo com que o usuário, além de contar com atributos pré-definidos, possa gerenciar seus próprios atributos. 


\subsubsection{As mensagens da Biblioteca}

No modelo original de MobiCS, cada mensagem é associada, no momento de sua definição, a uma única classe contento o seu respectivo manipulador. Tal característica impede a sua reutilização na implementação de outros protocolos. Um exemplo é a mensagem Ack que está presente na maioria dos protocolos de entrega de mensagens. Sua estrutura no modelo original de MobiCS para o protocolo RDP é como o mostrado na figura 4.10. Como pode-se observar, especifica-se no construtor da mensagem a classe que contém o método manipulador para esta mensagem. Tal fato impossibilita a reutilização dessa mensagem tanto por outros protocolos quanto por outros elementos de rede que também possam vir a tratar tal mensagem. Nesse modelo é necessário definir uma nova mensagem para cada tipo de elemento de rede que precise tratá-la.

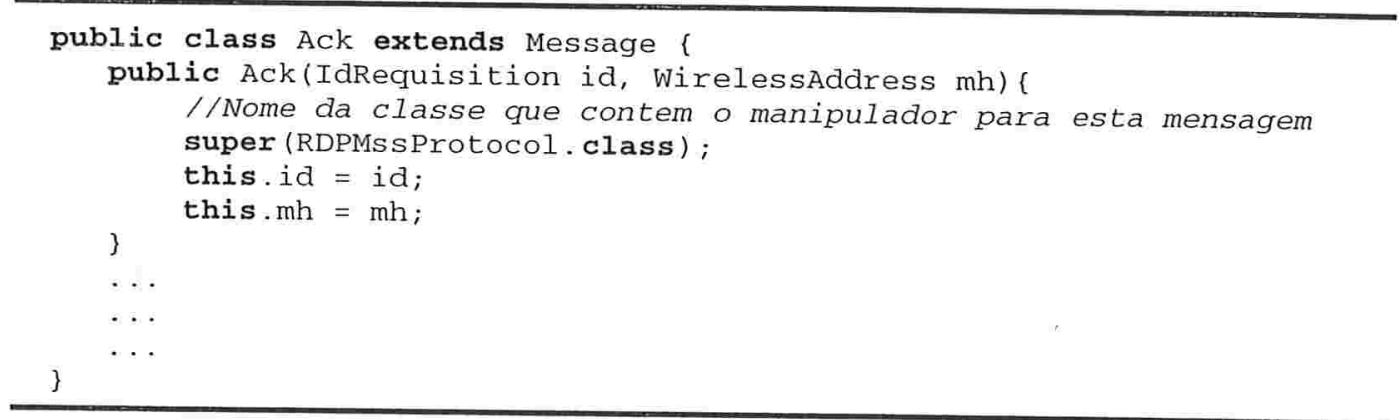

Figura 4.10: Classe Ack

Para tornar as mensagens reutilizáveis por outros protocolos ou por diferentes elementos de rede num mesmo protocolo, a biblioteca implementa tais mensagens com uma pequena modificação no construtor da mensagem. Agora a classe contendo o método manipulador é especificada como um parâmetro na criação da mensagem. Dessa forma, apenas uma instância da mensagem fica associada a um protocolo ou elemento de rede específico. Na figura 4.11, é mostrada a nova estrutura da mensagem Ack incorporada pela biblioteca. 


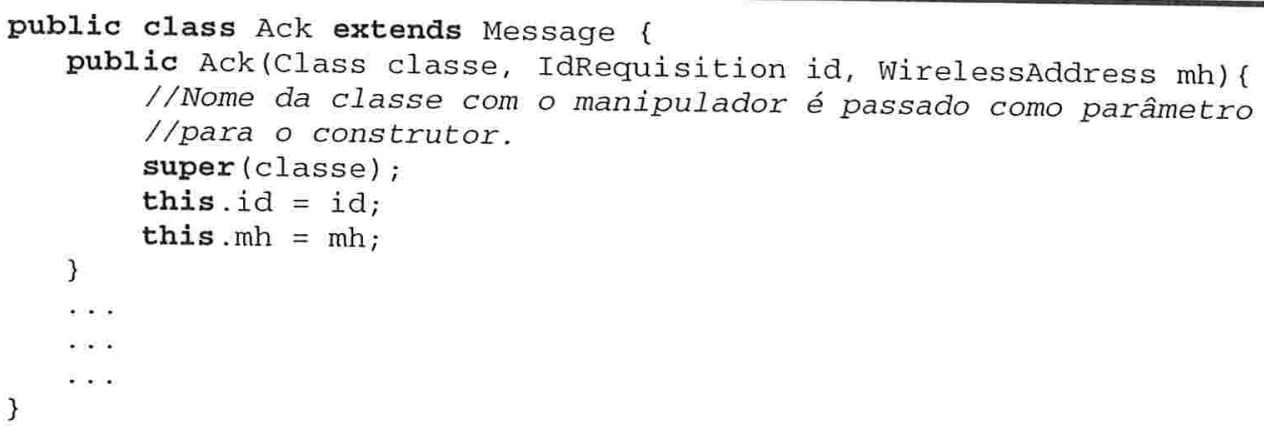

Figura 4.11: Classe Ack da Biblioteca

\subsubsection{O pacote estocástico}

Partindo de um estudo mais detalhado do modelo de simulação estocástica do MobiCS, observamos que muitas tarefas de programação que poderiam vir previamente implementadas pelo simulador são deixadas a cargo do usuário.

Numa simulação estocástica, o usuário deveria definir um conjunto de pequenas classes especificando modelos para os possíveis eventos, tais como desconexão e migração. Por exemplo, para definir o evento de migração o usuário deveria criar uma classe como a mostrada na figura 4.12.

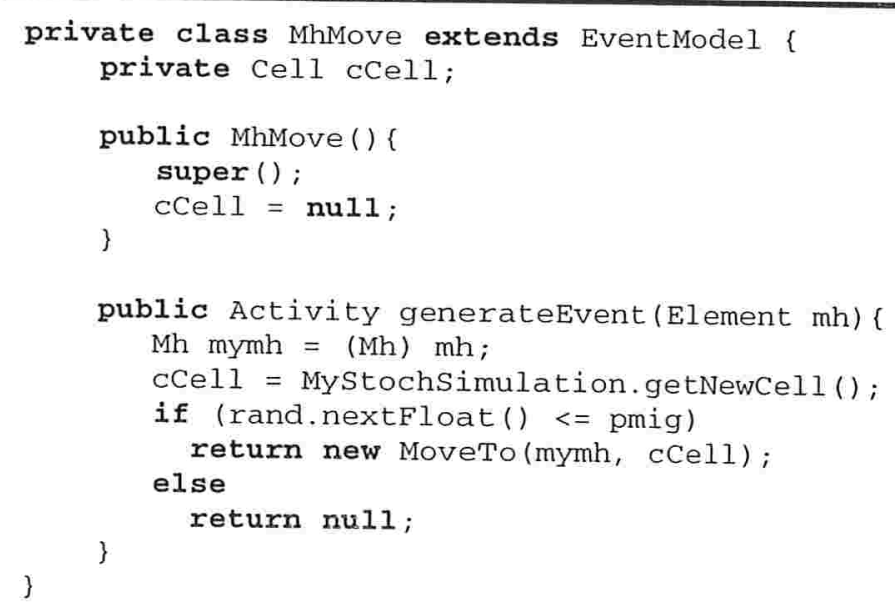

Figura 4.12: Exemplo de modelo de evento 
Todos os possíveis eventos são subclasses de EventModel e devem implementar um método chamado generateEvent recebendo como parâmetro um objeto da classe Element para o qual o evento deve ser gerado e retorna um objeto da classe Activity que é o evento propriamente dito.

Definidos os eventos, eles devem ser adicionados ao construtor de uma subclasse de EventGenerator que é responsável por definir o modelo de simulação para cada máquina simulada. Nesta classe, é definido em que período de tempo cada um dos eventos deve ser gerado. Criado o modelo de simulação, o usuário constrói a simulação propriamente dita e, na criação de cada máquina simulada, especifica o modelo de simulação associado.

Como forma de reduzir ao máximo o trabalho necessário para se implementar uma simulação estocástica em MobiCS, a biblioteca implementa um conjunto de classes que contém toda a funcionalidade mapeada, visando reduzir o trabalho de implementação de uma simulação.

A biblioteca implementa os eventos que devem integrar a maioria das simulações estocásticas. Os eventos são:

1. Inicialização - Escolha de uma célula inicial para cada Mh

2. Migração

3. Requisição

4. Desconexão

5. Reconexão

Para cada um desses eventos, foram criadas subclasses de EventModel que, baseado em valores de probabilidade, geram o evento correlato.

A biblioteca também possui a classe MhDeliveryEG que incorpora cada um dos eventos mapeados. Uma instância dessa classe é associada a cada Mh de forma que o simulador gere os eventos de acordo com probabilidades pré-determinadas. 
Uma contribuição importante da biblioteca na tentativa de facilitar o processo de implementação de simulações estocásticas é a criação de uma classe, chamada BehaviorPattern, que contém todas as informações necessárias a uma simulação. As informações que devem ser especificadas na instanciação dessa classe são:

- Número de Mh's

- Número de Requisições a serem geradas

- Probabilidade de Migração

- Probabilidade de Envio de Requisição

- Probabilidade de Desconexão

- Probabilidade de Reconexão

- Lista com as probabilidades de atração de cada Mss

Uma vez criada uma instância dessa classe, ela servirá como objeto de consulta para todas as outras classes da simulação estocástica. A criação desta classe evita possíveis erros de programação decorrentes da passagem desses vários parâmetros a todas as classes que os utilizam.

Outro componente do pacote estocástico é a classe DeliveryStochSimulation. Ela basicamente define um método para a escolha da nova célula para onde um dado Mh deve migrar uma vez que esta migração foi determinada. Essa escolha é baseada na lista de vizinhos da célula atual e na probabilidade de atração de cada uma. Esta classe deve ser estendida pelo usuário para a criação da simulação. O construtor da superclasse deve ser chamado, passando como parâmetro uma instância da classe BehaviorPattern contendo todas as informações necessárias à simulação, como descrito anteriormente. 


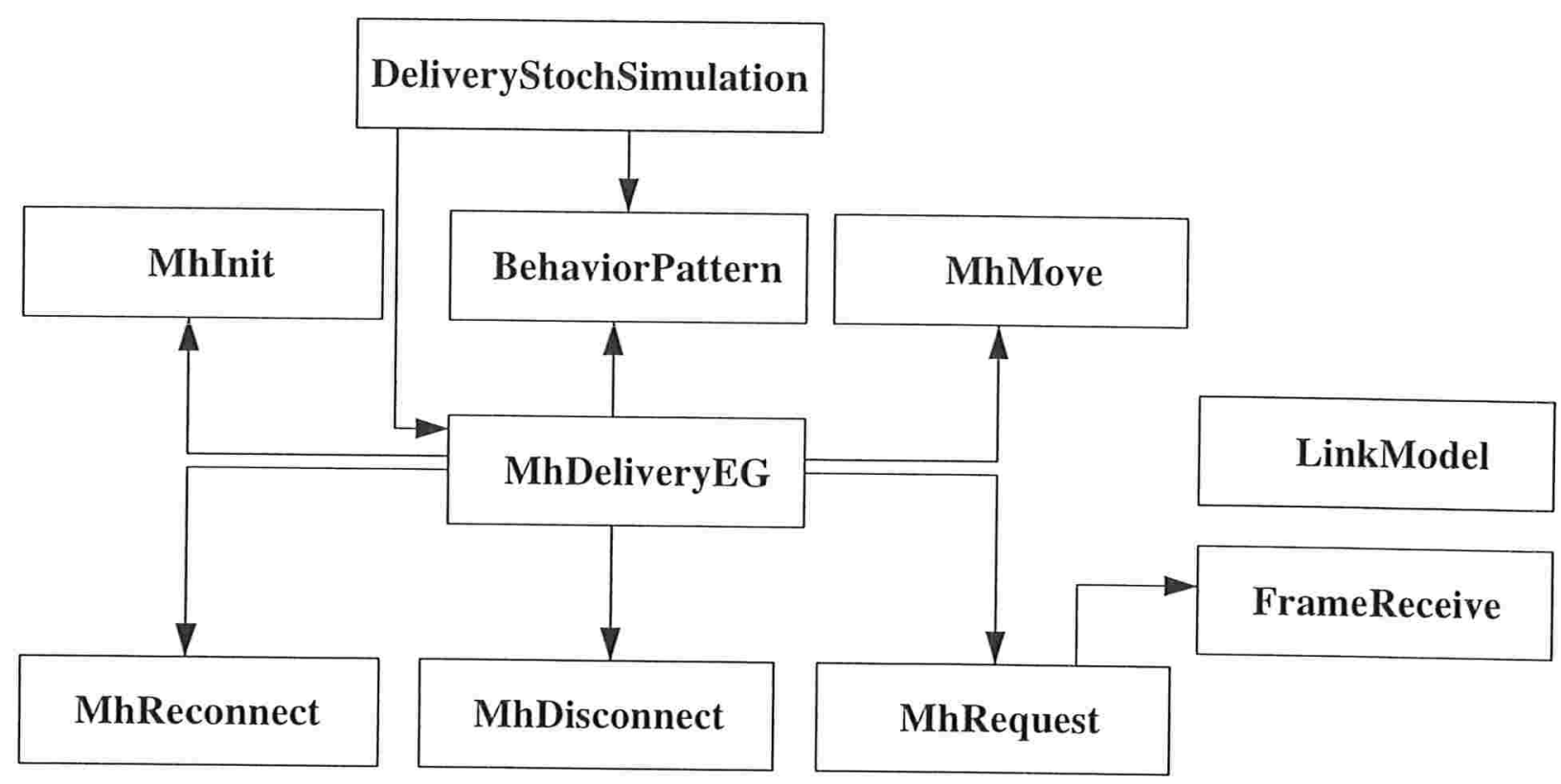

Figura 4.13: Pacote estocástico

O diagrama de classes do pacote estocástico é mostrado na figura 4.13.

A classe LinkModel do pacote estocástico é utilizada para definir um modelo de simulação para canais de comunicação. Esta classe permite definir um atraso associado ao envio de uma mensagem pelo canal de comunicação.

Existe ainda a classe FrameReceive, subclasse de Activity, utilizada internamente no pacote pela classe MhRequest para definir o evento de envio de uma requisição. 


\section{Capítulo 5}

\section{O uso da biblioteca}

\subsection{Protocolos Implementados}

Como forma de facilitar a implementação da Biblioteca e comprovar a melhoria na usabilidade do simulador MobiCS com a criação da biblioteca, foram implementados três protocolos de entrega de mensagens discutidos no Capítulo 3: O RDP, SRDP e MobileIP. A partir da implementação desses três protocolos, obtivemos a Tabela 5.1. Esta tabela mostra a considerável redução no número de linhas de código que precisam ser escritas para cada um dos protocolos depois da criação da biblioteca ${ }^{1}$.

\begin{tabular}{|l|c|c|c|}
\hline & RDP & SRDP & Mobile IP \\
\hline Com a Biblioteca & 582 & 442 & 927 \\
\hline Sem a Biblioteca & 1285 & 1063 & 1561 \\
\hline
\end{tabular}

Tabela 5.1: Número de linhas de código necessárias

\footnotetext{
${ }^{1} \mathrm{O}$ número de linhas de código leva em consideração o código dos protocolos e das simulações estocásticas.
} 


\subsection{Implementação do protocolo RDP}

Para ilustrar a implementação de protocolos utilizando a biblioteca, tomou-se como exemplo o protocolo RDP descrito na seção 3.2 do Capítulo 3.

Para implementar o RDP com o auxilio da biblioteca, foi necessário inicialmente definir as mensagens adicionais não existentes na biblioteca. São elas:

1. Arrive - Mensagem indicativa de mudança de célula.

2. DeReg - Mensagem para a remoção do registros de um Mh.

3. DeRegAck - Mensagem para confirmação de uma remoção.

4. UpdateCurrLoc - Atualização da localização de um Mh no proxy atual.

Definidas as mensagens, deve-se estender a classe SemiFixProxyMssProtocol que contém a implementação do manipuladores para as mensagens definidas pela biblioteca que devem ser tratadas pelos Mss's. A subclasse criada, aqui chamada de RDPMssProtocol, contém a implementação do manipuladores para todas as mensagens adicionais definidas pelo usuário. Eventualmente, algum manipulador pré-existente pode ser re-escrito caso o usuário queira dar um tratamento diferenciado para uma dada mensagem da biblioteca.

Os métodos manipuladores para as mensagens tratadas pelos Mh's e servidores já encontramse definidos nas classes SemiFixProxyMhProtocol e DeliveryServerProtocol, respectivamente.

A definição das mensagens e dos manipuladores para cada elemento de rede finalizam o processo de implementação do protocolo, resta agora criar as classes que representam os elementos de rede e a simulação em si.

Representando o elemento de rede Mss, foi criada a classe MyStochMss. Ela cria uma instância da classe contendo os manipuladores, chamada de RDPMssProtocol, que é registrada 
junto ao simulador como possuidora dos manipuladores para as mensagens que podem ser recebidas pelos Mss's do sistema.

Para os Mh's foi criada a classe MyStochMh. Ela instancia uma classe da biblioteca chamada SemiFixProxyMhProtocol que possui a implementação dos manipuladores e das estruturas de dados necessárias ao Mh no protocolo RDP. Essa instância é registrada junto ao simulador como possuidora dos manipuladores para as mensagens que podem ser recebidas pelos Mh's do sistema. Caso seja necessário definir qualquer manipulador adicional a classe SemiFixProxyMhProtocol deve ser estendida para permitir a definição dos manipuladores adicionais na subclasse. Finalizando a implementação da classe MyStochMh ela possui um método chamado onGreet() que retorna a mensagem a ser enviada ao novo Mss numa migração e outro método que retorna uma nova mensagem de requisição, chamado onRequest(). A figura 5.1 mostra a implementação da classe MyStochMh.

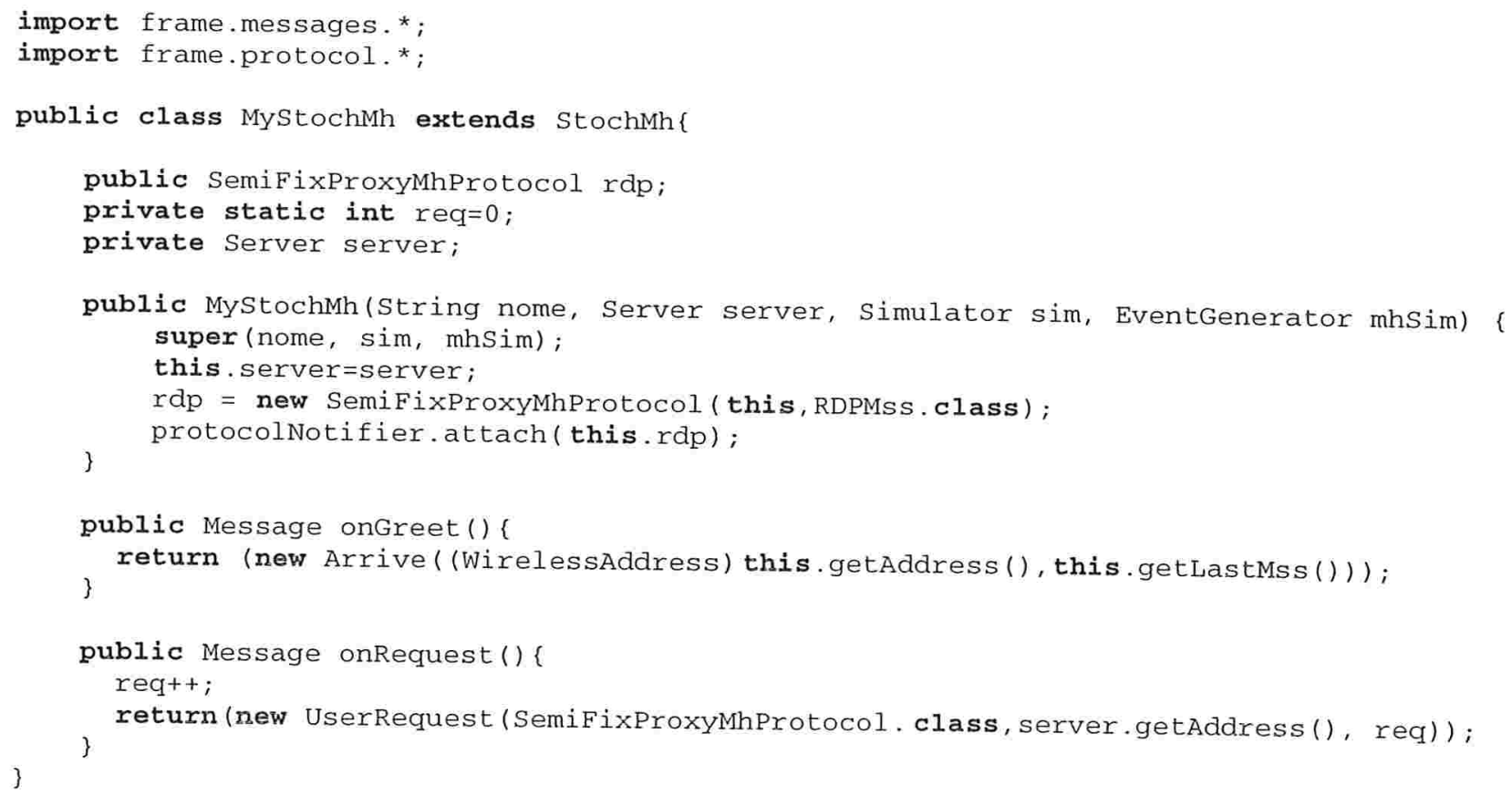

Figura 5.1: Classe MyStochMh 
O elemento de rede Servidor é representado pela classe MyStochServer. A implementação do protocolo do Servidor é feita instanciando a classe DeliveryServerProtocol que também já possui todos os manipuladores necessários ao Servidor no protocolo RDP. Da mesma maneira, qualquer manipulador para uma mensagem adicional definida pelo usuário deve ser definido numa subclasse de DeliveryServerProtocol.

A última fase na implementação é a criação do ambiente simulado. Nessa fase, o usuário deve estender a classe DeliveryStochSimulation do pacote frame.stoch da biblioteca. A subclasse foi chamada de MyStochSimulation. Essa subclasse implementa o método configure () no qual são criados os Mss's, Mh's e servidores do sistema, a cada um desses elementos de rede pode ser atribuído um gerador de eventos responsável por agendar a execução de eventos em períodos de tempo pré-determinados. Nessa fase, as células também são criadas e as conexões e vizinhanças entre elas são estabelecidas. A figura 5.2 mostra a implementação da classe MyStochSimulation. 


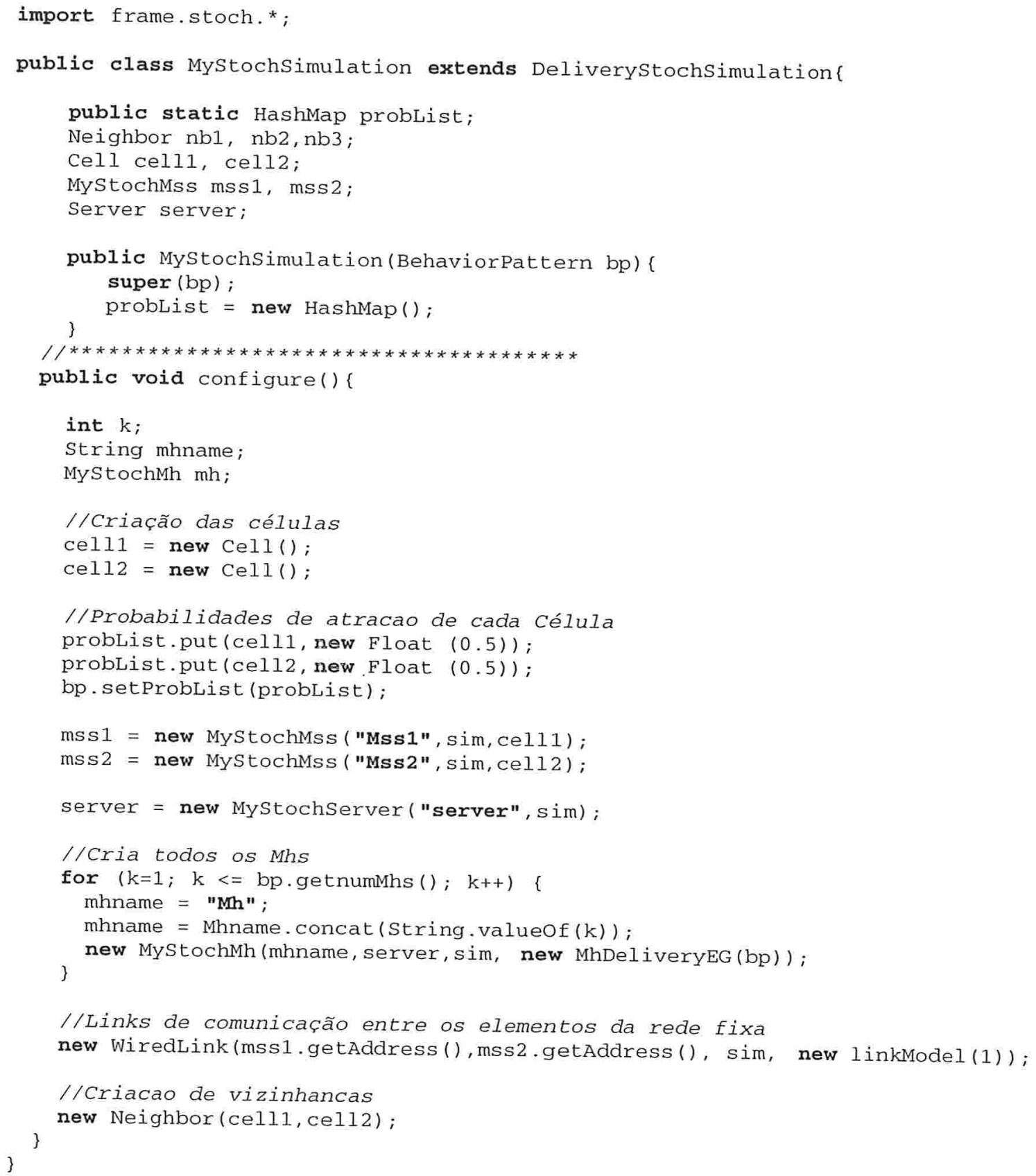

Figura 5.2: Classe MyStochSimulation 


\subsection{Resultados Obtidos}

A fim de verificar se a inserção de uma nova camada no modelo decorrente da criação da Biblioteca afeta o tempo gasto numa simulação, foram realizadas algumas simulações com os três protocolos implementados. Considerando que o objetivo principal das simulações aqui realizadas é avaliar o impacto da utilização da biblioteca na simulação de protocolos, optou-se por fixar a maior parte dos parâmetros de simulação e as probabilidades associadas.

\section{- Configuração da rede}

- Número de Mh's: Manteve-se em todas as simulações o mesmo número de $\operatorname{Mh}$ 's $\left(N_{M h s}=20\right)$;

- Número de células: Foram utilizadas 4 células interconectadas entre si;

- Posicionamento inicial dos Mh's: No início da simulação escolhe-se aleatoriamente uma célula para cada Mh.

\section{- Probabilidades associadas}

- Probabilidade de Desconexão: Estabeleceu-se o valor de 0.5 para a probabilidade dos Mh's ficarem desconectados da rede fixa;

- Probabilidade de Reconexão: O mesmo valor de probabilidade $\left(P_{r e c}=0.5\right)$ foi usado para a reconexão à rede fixa;

- Probabilidade de Migração: A probabilidade de um Mh mudar para uma nova célula foi fixada em 0.5 ;

- Probabilidade de Requisição: Cada Mh tinha uma probabilidade de 0.5 de realizar uma requisição; 
- Fator de Atração: Para cada célula foi atribuído um fator de atração de 0.25, de forma que cada célula tenha igual chance de ser escolhida como célula destino de um Mh.

Fixados os valores acima, foram executadas um total de 10 rodadas de simulação para cada protocolo variando o número de requisições de 50 a 500 requisições. Para cada número de requisições a simulação foi repetida 10 vezes e os tempos de cada repetição foram coletados. Esse procedimento foi executado tanto utilizando a biblioteca quanto sem o seu uso.

A partir dos dados coletados, calculou-se o tempo médio de execução para cada número de requisições. Gráficos foram construídos para ilustrar melhor os resultados obtidos. As figuras 5.3, 5.4 e 5.5 mostram graficamente os resultados das simulações feitas com os protocolos.

Na simulação do protocolo RDP, mostrada graficamente na figura 5.3, ocorreu uma perda linear de desempenho nas simulações realizadas com a biblioteca em relação às realizadas sem o seu uso. Já na simulação do protocolo SRDP mostrada na figura 5.4 observou-se que a perda de desempenho é praticamente constante.

O gráfico da figura 5.5 mostra os dados obtidos a partir da simulação do protocolo Mobile IP. Como se pode observar, as curvas se comportam de maneira parecida com as do protocolo RDP. Mais uma vez houve uma certa perda de desempenho ao se utilizar a biblioteca. 


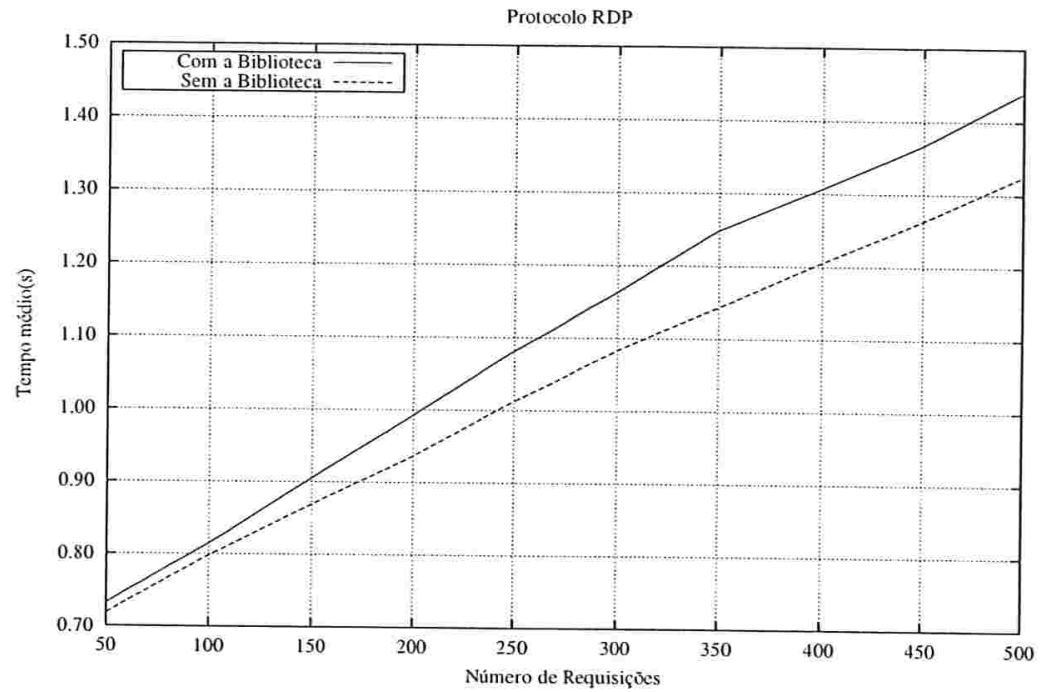

Figura 5.3: Simulação do protocolo RDP

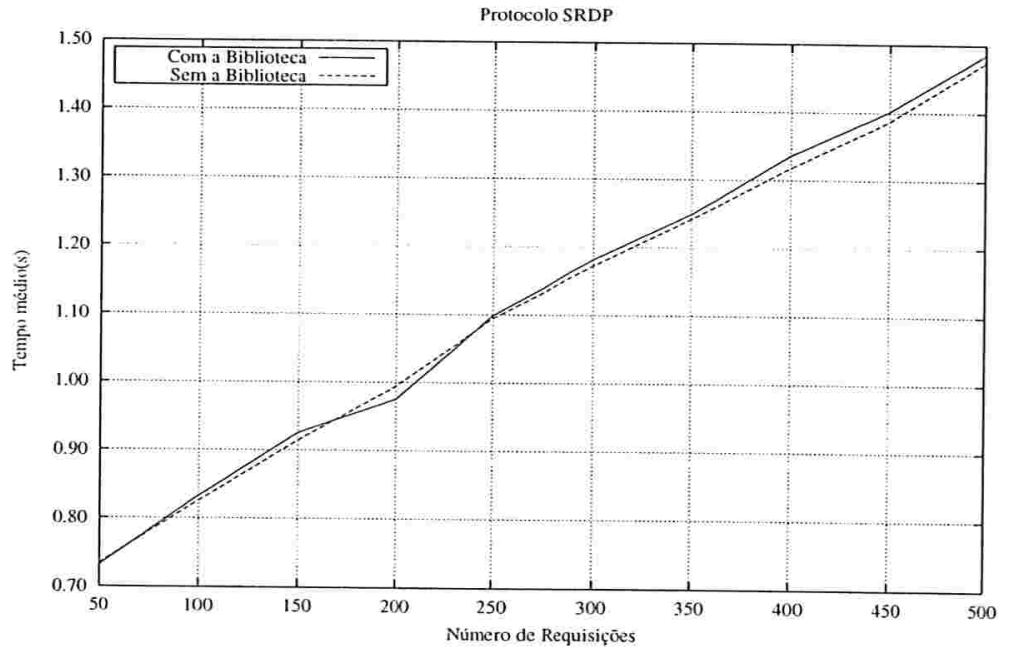

Figura 5.4: Simulação do protocolo SRDP 


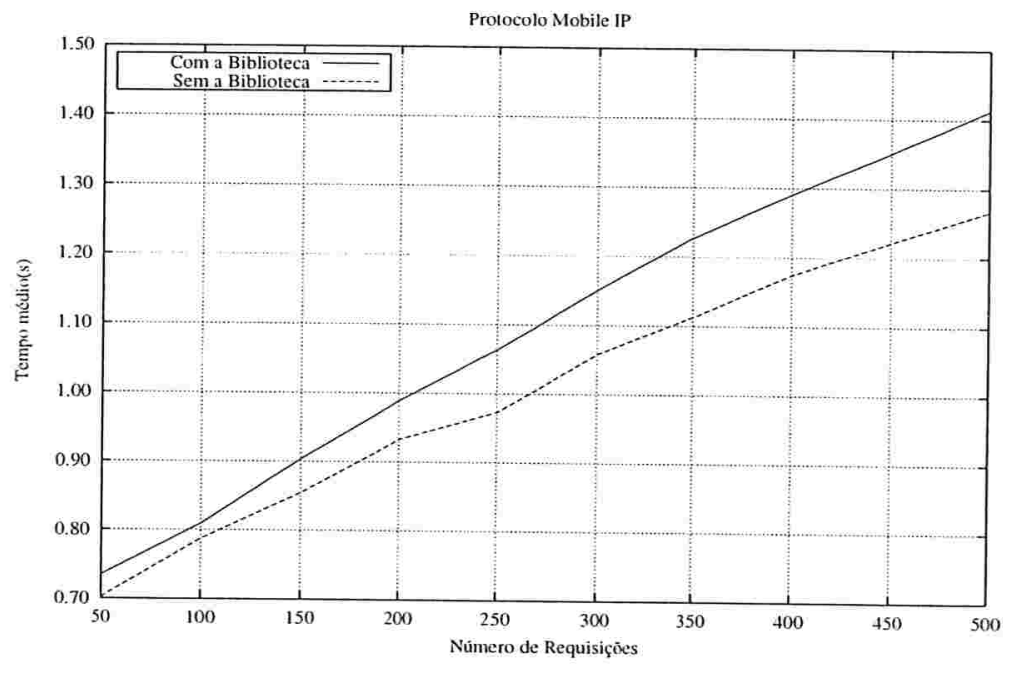

Figura 5.5: Simulação do protocolo Mobile IP

Analisando os gráficos obtidos, pode-se observar que houve uma pequena perda de desempenho com o uso da biblioteca nas simulações dos protocolos. Tal perda já era esperada considerando que foi inserido mais um nível hierárquico na implementação de protocolos e, em linguagens como Java que utiliza a resolução dinâmica de métodos, existe um custo adicional. No entanto, pode-se observar que a perda é, na maior parte dos casos, linear quando comparada às simulações realizadas sem a utilização da biblioteca.

Como forma de garantir que os tempos médios utilizados na criação dos gráficos têm um valor representativo, as tabelas a seguir mostram o tempo médio e o desvio padrão dos tempos calculados para cada número de requisições. Como se pode observar, os valores de desvio padrão em todas as tabelas são menores que $3 \%$ comprovando a representatividade dos valores médios. 


\begin{tabular}{|c|c|c|}
\hline Número de Requisições & Média & Desvio Padrão \\
\hline 50 & 0.73181818 & 0.01526623 \\
\hline 100 & 0.81454545 & 0.00890724 \\
\hline 150 & 0.90545455 & 0.01233151 \\
\hline 200 & 0.99272727 & 0.01285649 \\
\hline 250 & 1.08181818 & 0.02166614 \\
\hline 300 & 1.16363636 & 0.01871933 \\
\hline 350 & 1.24909091 & 0.01311110 \\
\hline 400 & 1.30727273 & 0.01958242 \\
\hline 450 & 1.36727273 & 0.02452861 \\
\hline 500 & 1.44000000 & 0.02412091 \\
\hline
\end{tabular}

Tabela 5.2: Protocolo RDP com uso da biblioteca

\begin{tabular}{|c|c|c|}
\hline Número de Requisições & Média & Desvio Padrão \\
\hline 50 & 0.71818182 & 0.02757409 \\
\hline 100 & 0.79818182 & 0.01585054 \\
\hline 150 & 0.86909091 & 0.01781447 \\
\hline 200 & 0.93636364 & 0.01871933 \\
\hline 250 & 1.01272727 & 0.02299838 \\
\hline 300 & 1.08363636 & 0.01666391 \\
\hline 350 & 1.14363636 & 0.02672171 \\
\hline 400 & 1.20545455 & 0.02571297 \\
\hline 450 & 1.26363636 & 0.02384523 \\
\hline 500 & 1.32545455 & 0.02965365 \\
\hline
\end{tabular}

Tabela 5.3: Protocolo RDP sem uso da biblioteca 


\begin{tabular}{|c|c|c|}
\hline Número de Requisições & Média & Desvio Padrão \\
\hline 50 & 0.73090909 & 0.00995859 \\
\hline 100 & 0.83272727 & 0.01285649 \\
\hline 150 & 0.92545455 & 0.01924183 \\
\hline 200 & 0.97545455 & 0.07475580 \\
\hline 250 & 1.09909091 & 0.00668043 \\
\hline 300 & 1.18181818 & 0.01028519 \\
\hline 350 & 1.24909091 & 0.01564059 \\
\hline 400 & 1.33636364 & 0.01149919 \\
\hline 450 & 1.40181818 & 0.00574960 \\
\hline 500 & 1.48545455 & 0.01499311 \\
\hline
\end{tabular}

Tabela 5.4: Protocolo SRDP com uso da biblioteca

\begin{tabular}{|c|c|c|}
\hline Número de Requisições & Média & Desvio Padrão \\
\hline 50 & 0.73363636 & 0.03914373 \\
\hline 100 & 0.82545455 & 0.00890724 \\
\hline 150 & 0.91454545 & 0.00890724 \\
\hline 200 & 0.99454545 & 0.01499311 \\
\hline 250 & 1.09454545 & 0.00890724 \\
\hline 300 & 1.17272727 & 0.01285649 \\
\hline 350 & 1.24181818 & 0.01585054 \\
\hline 400 & 1.31818182 & 0.01585054 \\
\hline 450 & 1.38727273 & 0.01285649 \\
\hline 500 & 1.47454545 & 0.01233151 \\
\hline
\end{tabular}

Tabela 5.5: Protocolo SRDP sem uso da biblioteca 


\begin{tabular}{|c|c|c|}
\hline Número de Requisições & Média & Desvio Padrão \\
\hline 50 & 0.73454545 & 0.01924183 \\
\hline 100 & 0.80909091 & 0.00995859 \\
\hline 150 & 0.90363636 & 0.01431638 \\
\hline 200 & 0.98909091 & 0.00995859 \\
\hline 250 & 1.06363636 & 0.02672171 \\
\hline 300 & 1.15090909 & 0.02151302 \\
\hline 350 & 1.22727273 & 0.01762793 \\
\hline 400 & 1.29090909 & 0.01975051 \\
\hline 450 & 1.35090909 & 0.02151302 \\
\hline 500 & 1.41272727 & 0.01762793 \\
\hline
\end{tabular}

Tabela 5.6: Protocolo Mobile IP com uso da biblioteca

\begin{tabular}{|c|c|c|}
\hline Número de Requisições & Média & Desvio Padrão \\
\hline 50 & 0.70181818 & 0.01336085 \\
\hline 100 & 0.78727273 & 0.01285649 \\
\hline 150 & 0.85454545 & 0.01499311 \\
\hline 200 & 0.93272727 & 0.01762793 \\
\hline 250 & 0.97272727 & 0.01285649 \\
\hline 300 & 1.05818182 & 0.01585054 \\
\hline 350 & 1.11272727 & 0.02135880 \\
\hline 400 & 1.17454545 & 0.01724879 \\
\hline 450 & 1.22181818 & 0.01336085 \\
\hline 500 & 1.26727273 & 0.02987578 \\
\hline
\end{tabular}

Tabela 5.7: Protocolo Mobile IP sem uso da biblioteca

Para calcular mais precisamente como se comporta a perda de desempenho com a inserção da biblioteca, foram construídos os gráficos das figuras 5.6, 5.7 e 5.8 que mostram a diferença entre os tempos médios de execução dos protocolos com e sem o uso da biblioteca. Como se pode observar, a diferença entre os tempos médios de execução crescem de maneira linear nos protocolos RDP e MobileIP. Já no protocolo SRDP essa diferença é praticamente constante. 


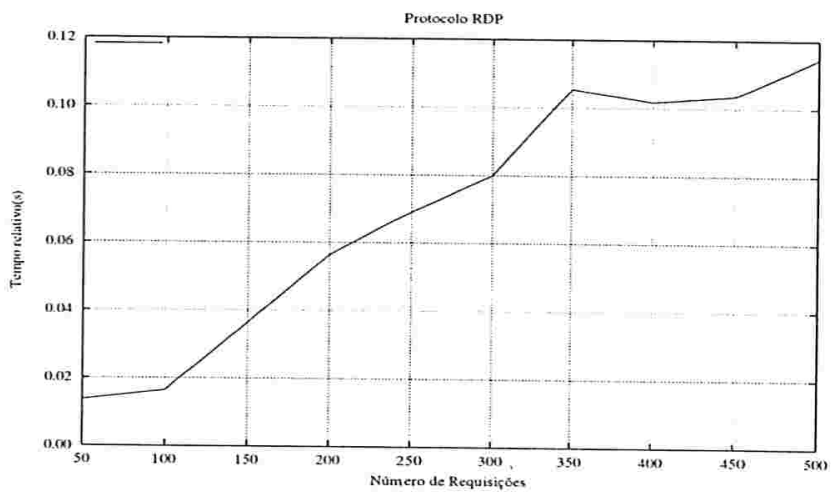

Figura 5.6: Variação relativa do tempo para o protocolo RDP

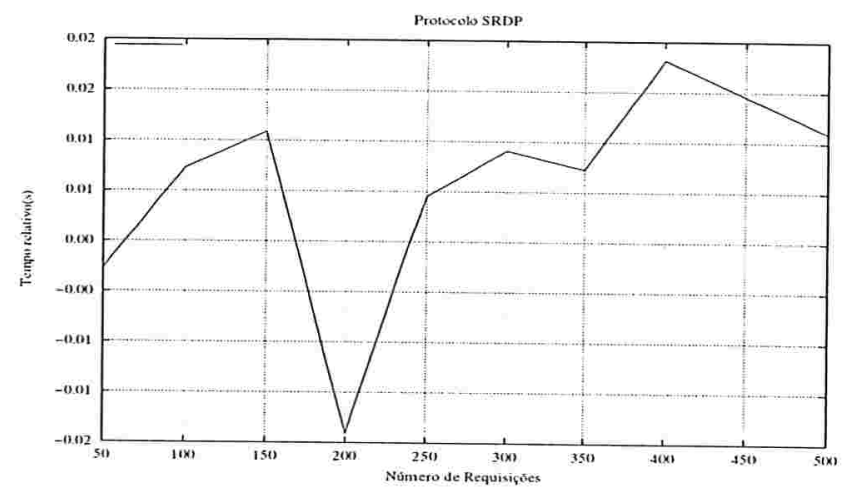

Figura 5.7: Variação relativa do tempo para o protocolo SRDP

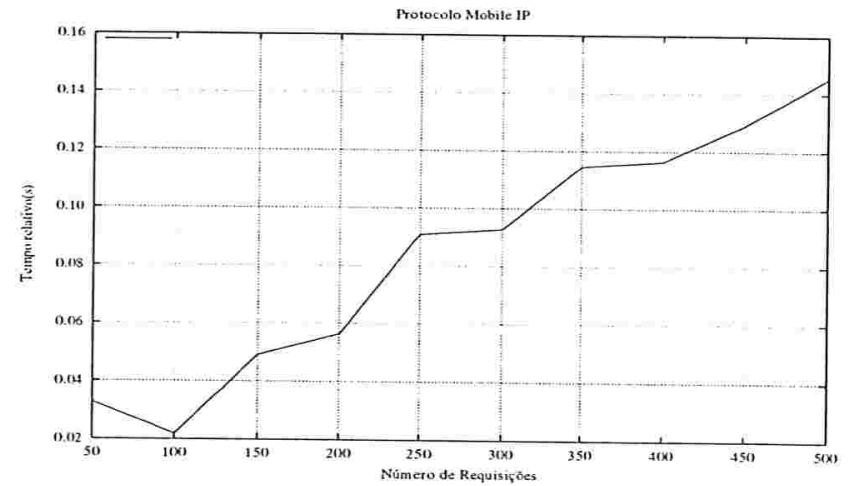

Figura 5.8: Variação relativa do tempo para o protocolo Mobile IP 


\section{Capítulo 6}

\section{Conclusões e Trabalhos Futuros}

Esta dissertação apresentou um estudo realizado sobre os protocolos de entrega de mensagens em redes móveis extraindo as semelhanças e diferenças entre os protocolos. Inicialmente foi realizada uma busca bibliográfica por protocolos pertencentes à classe em questão. Foram encontrados apenas dois protocolos: RDP e SRDP. Foi possível ainda a adaptação de outros dois protocolos: o Mobile IP e o Snapshot. Para cada um dos quatro protocolos, especificou-se as mensagens geradas, as informações que devem ser mantidas pelo sistema e a mecânica de funcionamento. Partindo dessa especificação, foi feita uma análise comparativa dos protocolos mostrando a que situações cada protocolo melhor se adequa. Além disso, essa análise mostrou a existência de certas semelhanças entre os protocolos estudados.

Como resultado do mapeamento das semelhanças existentes entre os protocolos de entrega de mensagens foi implementada uma biblioteca que visa prover ao usuário um conjunto de novas classes que facilitem a implementação de protocolos num simulador pré-existente chamado MobiCS [Roc01].

A biblioteca implementada provê um conjunto de mensagens comuns à classe de protocolos em questão mapeadas a partir da observação dos protocolos encontrados na bibliografia, tais mensagens permitem a inserção de novos parâmetros não mapeados. A Biblioteca possui 
também um conjunto de classes com os métodos manipuladores para as mensagens mapeadas. Existe ainda um pacote para reduzir e facilitar o trabalho de implementação de uma simulação estocástica.

Finalizada a implementação da biblioteca, partiu-se para comprovar a usabilidade da mesma. Para isso, foram implementados três protocolos e verificou-se uma redução considerável no número de linhas de código necessárias, em torno de $50 \%$.

Apesar de ficar comprovado uma certa perda de desempenho com o uso da biblioteca, decorrente da inserção de mais uma camada no modelo de implementação, constatou-se que a interferência de tal perda na simulação de protocolos é praticamente linear o que torna aceitável o seu uso.

Uma importante contribuição desta dissertação foi o conjunto de modificações realizadas no simulador MobiCS decorrentes da observação dos protocolos de entrega de mensagens. A implementação dessas modificações incorporaram ao simulador características como, por exemplo, o estabelecimento de vizinhanças entre células que tornaram as simulações mais condizentes com a realidade.

Como consequência do estudo realizado, surgem alternativas para possíveis trabalhos futuros, são eles:

- Construir simulações mais robustas para os protocolos implementados a fim de analisar a veracidade da análise comparativa realizada no Capítulo 3. As simulações devem coletar informações como a quantidade de retransmissões necessárias para entrega de uma mensagem e quantidade de mensagens de hand-off geradas para um mesmo número de requisições, tanto para situações de intensa mobilidade quanto de baixa mobilidade. Coletadas essas informações, construir gráficos que ilustrem os resultados obtidos.

- Partindo de uma observação minuciosa do domínio do problema, mapear e implementar outras mensagens e manipuladores que ainda não foram incorporados à biblioteca. 
- A biblioteca permite que, através da composição das partes comuns aqui fatoradas, novos protocolos sejam criados e dessa forma aumente o número de protocolos para entrega de mensagens que ainda é muito reduzido.

- Utilizando-se da idéia de fatorar características comuns a um conjunto de protocolos, estender a biblioteca para dar suporte a outras classes de protocolos, tais como os protocolos de multicast.

- Desenvolvimento de uma linguagem para descrição de simulações. A especificação das simulações não mais seriam feitas em Java e sim numa linguagem projetada especificamente para esta tarefa como feito por Durham [DJ96b]. 


\section{Referências Bibliográficas}

[AB93] Arup Acharya and B.R. Badrinath. Delivering multicast messages in networks with mobile hosts. In 13th International Conference on Distributed Computing Systems, pages 292-299, Pittsburgh, US, May 1993.

[BAI93] B. R. Badrinath, A. Acharya, and T. Imielinski. Impact of mobility on distributed computations. In ACM Operating System Review, pages 15-20, New Brunswick, April 1993.

[BBIM93] B. R. Badrinath, A. Bakre, T. Imielinski, and R. Marantz. Handling mobile clients: A case for indirect interaction. In 4th Workshop on Workstation Operating Systems (WWOS-IV), pages 91-97, Napa, U.S., 1993.

[BBIM94] B. R. Badrinath, A. Bakre, T. Imielinski, and R. Marantz. Designing distributed algorithms for mobile computing networks. In Computers and Communications, 1994.

$\left[\mathrm{BEF}^{+} 00\right]$ Lee Breslau, Deborah Estrin, Kevin Fall, Sally Floyd, John Heidemann, Ahmed Helmy, Polly Huang, Steven McCanne, Kannan Varadhan, Ya Xu, and Haobo Yu. Advances in network simulation. In IEEE Computer, pages 33(5):59-67, Maio 2000. 
[Bha96] Nina Trappe Bhatti. A System for Constructing Configurable High-Level Protocols. PhD thesis, University of Arizona, December 1996.

[BHSC98] Nina T. Bhatti, Matti A. Hiltunen, Richard D. Schlichting, and Wanda Chiu. Coyote: a system for constructing fine-grain configurable communication services. In Transaction on Computer Systems, volume 16(4), pages 321-366. ACM, November 1998.

$\left[\mathrm{BMJ}^{+98]}\right.$ Josh Broch, David A. Maltz, David B. Johnson, Yih-Chun Hu, and Jorjeta Jetcheva. A performance comparison of multi-hop wireless ad hoc network routing protocols. In 4th Annual ACM/IEEE International Conference on Mobile Computing and Networking(MOBICOM-98), pages 85-97, New York, Outubro 25-30 1998.

[BMSU01] Prosenjit Bose, Pat Morin, Ivan Stojmenovic, and Jorge Urrutia. Routing with guaranteed delivery in ad hoc wireless networks. Wireless Networks, 7(6):609-616, 2001.

$\left[\mathrm{BMT}^{+} 98\right]$ Rajive Bagrodia, Richard Meyer, Mineo Takai, Yu an Chen, Xiang Zeng, Jay Martin, and Ha Yoon Song News. Parsec: A parallel simulation environment for complex systems. In IEEE Computer, pages 31(10):77-85, Outubro 1998.

[BS95] Kevin Brown and Suresh Singh. RelM: Reliable multicast for mobile networks. Technical Report, Department of Computer Science, University of South Carolina, Setembro 1995.

[CB95] M. Scott Corson and Stephen Gordon Batsell. A reservation-based multicast $(\mathrm{RBM})$ routing protocol for mobile networks: Overview of initial route construction. In INFOCOM (3), pages 1063-1074, 1995. 
[CL85] K. M. Chandy and L. Lamport. Distributed snapshots: Determining global states of distributed systems. In Trans. on Computer Systems, volume 3(1), pages 63-75. ACM, Frebuary 1985.

[DFJ91] Daniel Duchamp, Steven K. Feiner, and Gerald Q. Maguire Jr. Software technology for wireless mobile computing. In IEEE Network Magazine, pages 12-18, Novembro 1991.

[DJ96a] Alan Durham and Ralph Johnson. A framework for run-time systems and its visual programming language. In OOPSLA96, Object-Oriented Programming Systems, Languages, and Applications, San jose, CA, Outubro 1996.

[DJ96b] Alan M. Durham and Ralph E. Johnson. An approach to designing menu-based languages. In TOOLS-USA96, Twentieth international conference and exhibition., Santa Bárbara, Califórnia, Julho 1996.

[DPS ${ }^{+94]}$ Alan Demers, Karin Petersen, Mike Spreitzer, Douglas Terry, Marvin Theimer, and Brent Welch. The bayou architecture: Support for data sharing among mobile users. In IEEE Workshop on Mobile Computing Systems and Applications, pages 2-7, Dezembro 1994.

[Dur01] Alan Mitchell Durham. A conectionless protocol for mobile agents. Relatório Técnico, Janeiro 2001.

[ESO00] M. Endler, D. Silva, and K. Okuda. RDP: A Result Delivery Protocol for Mobile Computing. In Int. Workshop on Wireless Networks and Mobile Computing (WNMC) with 20th ICDCS, Taiwan, April 2000. R.O.C. IEEE.

[ESS $\left.{ }^{+} 00\right]$ M. Endler, D. Silva, F. Silva, R. Rocha, and M. de Moura. Project SIDAM: Overview and preliminary results, May 2000. 
[FJL ${ }^{+99]}$ Maxime Flament, Niklas Johansson, Martin Lantz, Jonas Lindblom, Thomas Meincke, and Ola Wintzell. Enhanced personal digital assistant - the future of mobile information retrieval. In PCC Summer School 1999, Junho 1999.

[FSJ99] Mohamed E. Fayad, Douglas C. Schmidt, and Ralph E. Johnson. Building Application Frameworks. Wiley Computer Publishing, 1999.

[GHJV95] Erich Gamma, Richard Helm, Ralph Johnson, and John Vlissides. Design Patterns: Elements of Reusable Software. Addison-Wesley, 1995.

[Gol84] Adele Goldberg. Smalltalk-80: The Interactive Programming Environment. Addison-Wesley, 1984.

[HP91] Norman C. Hutchinson and Larry L. Peterson. The x-kernel: An architecture for implementing network protocols. In IEEE Transactions on Software Engineering, pages 64-76, January 1991.

[JM96] David B. Johnson and David A. Maltz. Protocols for adaptative wireless and mobile networking. In IEEE Personal Communications, 3(1), Frebuary 1996.

[LA97] L. M. Liljenstam and R. Ayani. Mobsim++: An environment for parallel simulation of pcns. In SCS World Congress on Systems Simulation(WCSS'97), Singapore, Setembro 1997.

[LL00] Chi-Wai Lin and Dik-Lun Lee. Adaptive data delivery in wireless communication environments. In 20th IEEE International Conference on Distributed Computing Systems, pages 10-13, Taiwan, Abril 2000.

[Mat96] Michael Mattsson. Object-Oriented Frameworks - A survey of methodological issues. PhD thesis, University College of Karlskrona/Ronneby, 1996. 
[ML98] Geraldo Robson Mateus and Antonio Alfredo Ferreira Loureiro. Introdução à Computação Móvel. 11a Escola de Computação, COPPE/Sistemas, NCE/UFRJ, 1998.

[MP99] Amy L. Murphy and Gian Pietro Picco. Reliable communication for highly mobile agents. In First International Symposium on Agent Systems and Applications (ASA'99)/Third International Symposium on Mobile Agents (MA'99), Palm Springs, CA, USA, 1999.

[PMJ94] Charles E. Perkins, Andrew Myles, and David B. Johnson. The Internet Mobile Host Protocol (IMHP). In INET, Junho 1994.

[PRS96] Ravi Prakash, Michel Raynal, and Mukesh Singhal. An efficient causal ordering algorithm for mobile computing environments. In International Conference on Distributed Computing Systems, pages 744-751, 1996.

[RBM00] Mudumbai Ranganathan, Marc Bednarek, and Doug Montgomery. A reliable message delivery protocol for mobile agents. In $A S A / M A$, pages 206-220, Setembro 2000 .

[RFV95] Luís E. T. Rodrigues, Henrique Fonsceca, and Paulo Veríssimo. Reliable computing over mobile networks, Agosto 1995.

[Roc01] Ricardo Couto Antunes da Rocha. Uma arquitetura para simulação flexível de protocolos para computação móvel. Master's thesis, Universidade de São Paulo, Maio 2001.

[RV98] L. Rizzo and L. Vicisano. RMDP: An FEC-based Reliable Multicast Protocol for Wireless Environments. In Mobile Computing and Communications Review, Volume 2, Number 2, April 1998. 
[Sch86] Kurt J. Schmucker. Object-Oriented Programming for the Macintosh. Hayden Book Company, 1986.

[Tab02] Lucy Mari Tabuti. Um estudo de um protocolo de comunicação para dispositivos móveis usando distributed join-calculus. Master's thesis, Universidade de São Paulo, Setembro 2002.

[Tak00] Tadao Takahashi. Sociedade da Informação no Brasil: Livro Verde. Ministério da Ciência e Tecnologia, Brasília, 2000.

[TUSM94] Fumio Teraoka, Keisuke Uehara, Hideki Sunahara, and Jun Murai. VIP: A protocol providing host mobility. Communications of the ACM, 37(8):67-75, 1994.

[ZBG98] X. Zeng, R. Bagrodia, and M. Gerla. Glomosim: A library for parallel simulation of large-scale wireless networks. In 12th Workshop on Parallel and Distributed Simulation(PADS-98), pages 154-161, Los Alamitos, Maio 26-29 1998. 